\title{
Oligohistidine and targeting peptide functionalized TAT-NLS for enhancing cellular uptake and promoting angiogenesis in vivo
}

\author{
Qian Li ${ }^{1}$, Xuefang Hao ${ }^{1}$, Syed Saqib Ali Zaidi , Jintang Guo ${ }^{1,2}$, Xiangkui Ren ${ }^{1,2 \dagger}$, Changcan Shi ${ }^{3,4 \dagger}$, \\ Wencheng Zhang ${ }^{5}$ and Yakai Feng ${ }^{1,2,6^{*}+}$ (D)
}

\begin{abstract}
Background: Gene therapy has been developed and used in medical treatment for many years, especially for the enhancement of endothelialization and angiogenesis. But slow endosomal escape rate is still one of the major barriers to successful gene delivery. In order to evaluate whether introducing oligohistidine $\left(H_{n}\right)$ sequence into gene carriers can promote endosomal escape and gene transfection or not, we designed and synthesized Arg-Glu-Asp-Val (REDV) peptide functionalized TAT-NLS-H ${ }_{n}$ (TAT: typical cell-penetrating peptide, NLS: nuclear localization signals, $H_{n}$ : oligohistidine sequence, $n: 4,8$ and 12) peptides with different $H_{n}$ sequence lengths. pEGFP-ZNF580 (pZNF580) was condensed by these peptides to form gene complexes, which were used to transfect human umbilical vein endothelial cells (HUVECs).

Results: MTT assay showed that the gene complexes exhibited low cytotoxicity for HUVECs. The results of cellular uptake and co-localization ratio demonstrated that the gene complexes prepared from TAT-NLS- $\mathrm{H}_{\mathrm{n}}$ with long $\mathrm{H}_{\mathrm{n}}$ sequence $(n=12)$ benefited for high internalization efficiency of pZNF580. In addition, the results of western blot analysis and PCR assay of REDV-TAT-NLS-H 12 /pZNF580 complexes showed significantly enhanced gene expression at protein and mRNA level. Wound healing assay and transwell migration assay also confirmed the improved proliferation and migration ability of the transfected HUVECs by these complexes. Furthermore, the in vitro and in vivo angiogenesis assay illustrated that these complexes could promote the tube formation ability of HUVECs.
\end{abstract}

Conclusion: The above results indicated that the delivery efficiency of pZNF580 and its expression could be enhanced by introducing $H_{n}$ sequence into gene carriers. The $H_{n}$ sequence in REDV-TAT-NLS- $H_{n}$ is beneficial for high gene transfection. These REDV and $H_{n}$ functionalized TAT-NLS peptides are promising gene carriers in gene therapy.

Keywords: Gene carrier, Peptide, Histidine, REDV, Targeting, HUVECs, pZNF580

\section{Background}

Nowadays, small-diameter artificial blood vessels $(<6 \mathrm{~mm})$ have been used in clinical treatment of cardiovascular diseases, but their long-term patency rate remains low [1,2]. To solve this problem, many surface modification strategies have been developed to enhance

\footnotetext{
*Correspondence: yakaifeng@tju.edu.cn

${ }^{\dagger}$ Xiangkui Ren, Changcan Shi and Yakai Feng contributed equally to this work

1 School of Chemical Engineering and Technology, Tianjin University,

Tianjin 300350, China

Full list of author information is available at the end of the article
}

the hemocompatibility of artificial blood vascular materials, such as grafting zwitterionic polynorbornene, phosphorylcholine, heparin, gelatin or silk fibroin to avoid platelet adhesion and aggregation [3-7].

The re-endothelialization of small-diameter artificial blood vessels is beneficial for high long-term patency. Surface modification with bioactive peptides, such as Arg-Gly-Asp (RGD) [8], Cys-Ala-Gly (CAG) [9] and Arg-Glu-Asp-Val (REDV), can promote the attachment to endothelial cells (ECs). Among these peptides, REDV peptide can be specially recognized by $\alpha 4 \beta 1$ integrin, which is enriched in ECs but lacked in smooth muscle 
cells (SMCs) $[10,11]$. Ji et al. proved that the combination of rapamycin-loaded polymer base layer and REDV peptide tethered top layer could promote the competitive adhesion of human umbilical vein endothelial cells (HUVECs) over human aortic smooth muscle cells, and enhanced in situ endothelialization [12]. Recently, our studies demonstrated that REDV-modified gene carriers could specially recognize ECs and selectively enhance transfection efficiency by transferring DNA into ECs so as to promote their proliferation and migration as well as vascularization in vitro and in vivo [13-16].

Gene therapy has been considered as an effective method for EC migration and proliferation, which benefits for rapid endothelialization and neovascularization [17]. For successful gene therapy, the major key task is to develop effective gene carriers. Compared with viral vectors, the synthesized gene carriers have gained much attention owing to their high safety, low cost and convenient preparation [18-20]. However, there still exist some biological barriers in gene delivery [21], such as low biocompatibility, DNA packaging ability, cellular uptake, endosomal escape [22] and DNA release [23].

Low cellular uptake is a major barrier in gene delivery because cell membrane acts as a significant physical obstacle for gene carriers. In recent years, gene delivery systems based on cationic peptides have been widely studied owing to their high biocompatibility and specific functions [24]. Compared with polymeric gene carriers, these peptide carriers exhibit nearly no cytotoxicity for cells. Cell-penetrating peptides (CPPs), a series of short arginine-rich cationic peptides, have the specific ability to cross cell membrane. They serve as a flexible strategy for overcoming the first barrier and further improving the gene delivery effect [25-29]. Tyr-Gly-Arg-Lys-LysArg-Arg-Gln-Arg-Arg-Arg (YGRKKRRQRRR, TAT peptide) is one of non-specific selectively CPPs [30], which was derived from human immunodeficiency viruses 1 (HIV-1) [31]. TAT has been proven to promote cellular uptake and gene delivery because of its high cell membrane penetration. Gao et al. modified the poly(N-isopropylacrylamide) (PNIPAM) microgel particles with TAT peptide to form PNIPAM-FL-TAT particle, which showed significantly high cellular internalization compared with the PNIPAM group [32].

Another key issue in gene delivery is whether therapeutic DNAs can effectively cross the nuclear pore complexes (NPCs) on the nuclear membrane into nucleus. Nuclear access is limited by small nuclear pore diameter (only $9 \mathrm{~nm}$ ), so only small molecules can be directly transported into nucleus through NPCs [33, 34]. Several methods have been investigated to specially translocate DNAs into nucleus, for example, gene carriers containing nuclear localization signal (NLS) peptides [35, 36]. One of the most well-known NLS peptides is Pro-Lys-LysLys-Arg-Lys-Val sequence (PKKKRKV), which is derived from the large $\mathrm{T}$ antigen of the SV40 virus and has been reported to improve the nuclear access and enhance gene delivery successfully. Zhang et al. used TAT-PKKKRKV peptide to carry $\mathrm{VEGF}_{165}$ plasmid to promote the expression of VEGF ${ }_{165}$ protein and angiogenesis [37]. TAT-NLS can transfer various cell styles without specificity and selectivity because the TAT peptide sequence possesses the ability to quickly enter into almost all live cells [38].

After cellular uptake, the gene complexes should rapidly escape from endosomal/lysosomal compartment [39, 40]. Many studies focused on the promotion of endosomal/lysosomal escape. Polycations, such as polyethyleneimine and polyamidoamine dendrimers, have the ability to destroy the endosomal membrane and escape from endosomes owing to the proton sponge effect. Polycations can catch large amount of protons and cause the influx of $\mathrm{Cl}^{-}$, leading to the disruption of endosome and release of DNAs into cytoplasm [41-44]. Moreover, histidine $(\mathrm{H})$-enriched gene carriers can also break the endosomal membrane due to the protonation of its imidazole ring. Imidazole ring facilitates gene delivery from endosome into cytosol because of its $\mathrm{pH}$ proton sponge effect $[45,46]$. It exhibits hydrophobic under physiological condition $(\mathrm{pH}=7.4)$ and becomes hydrophilic via protonating the unsaturated nitrogen in imidazole group in an acidic environment, such as endosome/lysosome $[47,48]$. At low $\mathrm{pH}$ value $(\mathrm{pH}<7.4), \mathrm{H}$-enriched gene carriers rupture the endosomal membrane and escape from endosomes [49]. Herein, in this paper, we aimed to design and prepare the EC targeting gene carriers based on CPPs, REDV and oligohistidine $\left(\mathrm{H}_{\mathrm{n}}, \mathrm{n}=4,8\right.$ and 12) to overcome the multiple barriers in the process of gene delivery. These multifunctional carriers possessed EC targeting function, high internalization efficiency, enhanced endosome/lysosome escape capacity as well as nucleus translocation ability.

In previous studies, enhanced green fluorescent protein (EGFP)-ZNF580 plasmid (abbreviated as pZNF580) was used to promote the proliferation and migration as well as angiogenesis ability of ECs. The expression of ZNF580 gene could promote vascular endothelial growth factor (VEGF) expression, which further enhanced the migration and proliferation of ECs [50-52]. In the present study, we synthesized the multifunctional peptide carriers with different length of oligohistidine sequence (REDVTAT-NLS- $\mathrm{H}_{4}$, REDV-TAT-NLS- $\mathrm{H}_{8}$ and REDV-TATNLS- $\mathrm{H}_{12}$ ) in order to enhance their endosome/lysosome escape. These peptides could condense with pZNF580 gene to form gene complexes. The condensation ability 
was evaluated by agarose gel electrophoresis test. The cellular uptake processes of REDV-TAT-NLS- $\mathrm{H}_{\mathrm{n}} / \mathrm{pZNF580}$ (abbreviated as peptide/pZNF580) complexes, delivery of genes into ECs and angiogenesis were illustrated in Fig. 1a. Oligohistidine sequence had many imidazole groups that undergo protonation in endosome, which facilitated for endosome/lysosome escape and gene delivery (Fig. 1b). The cell viability of the peptide/pZNF580 complexes were determined by MTT test. Furthermore, the cellular uptake and intracellular trafficking of the peptide/pZNF580 complexes were measured quantitatively and qualitatively by flow cytometry and confocal laser scanning microscopy (CLSM). Western blot analysis and PCR assay were used to evaluate ZNF580 gene expression of the transfected cells by different peptide/ pZNF580 complexes both at protein and mRNA level. The angiogenesis and tube formation ability of the transfected cells by peptide/pZNF580 complexes was evaluated in vitro and in vivo.

\section{Experimental section}

Materials

Peptides named REDV, REDV-YGRKKRRQRRRPKKKRKV (abbreviated as REDV-TAT-NLS- $\mathrm{H}_{0}$ ), REDV-YGRKKRRQRRR-PKKKRKV-HHHH (abbreviated as REDV-TAT-NLS- $\mathrm{H}_{4}$ ), REDV-YGRKKRRQRRR-PKKKRKV-HHHHHHHH (abbreviated as REDV-TAT-NLS- ${ }_{8}$ ) and REDV-YGRKKRRQRRR-PKKKRKV-HHHHHHHHHHHH (abbreviated as REDVTAT-NLS- $\mathrm{H}_{12}$ ) were synthesized by GL Biochem. Ltd. (Shanghai, China). 3-(4,5-Dimethyl-2-thiazolyl)-2,5-diphenyl-2-H-tetrazolium bromide (MTT) was obtained from Ding Guo Chang Sheng Biotech. Co., Ltd. (Beijing, China). Dulbecco's modified eagle medium (DMEM) and fetal bovine serum (FBS) were purchased from Invitrogen Corporation (Carlsbad, CA). Transwell chambers and Matrigel (Cat. Nos. 356234) was obtained from Corning Incorporated (New York, USA). TransScript First-Strand cDNA Synthesis SuperMix and TransStart ${ }^{\mathrm{TM}}$ Top Green qPCR SuperMix were purchased from Transgen Biotech

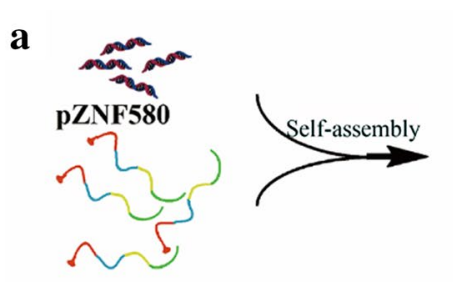

REDV-TAT- NLS- $H_{n}$
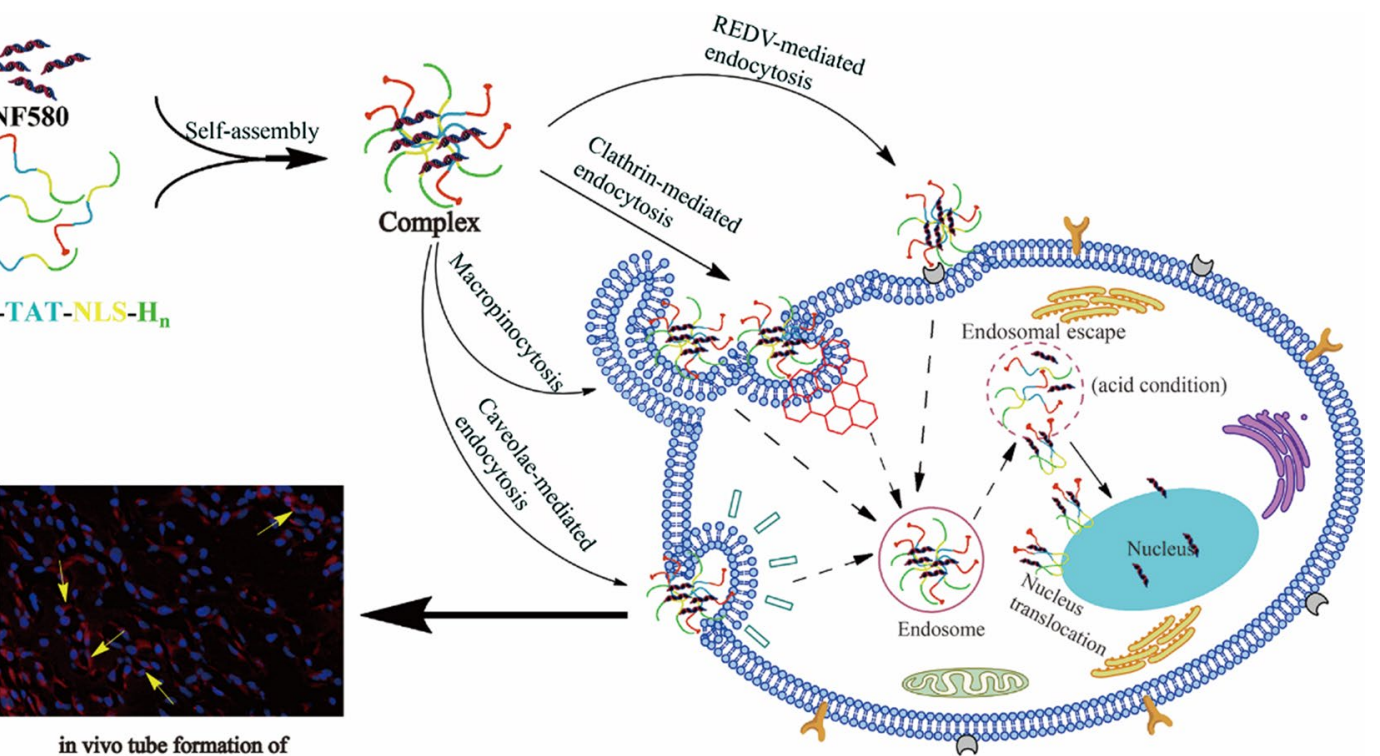

in vivo tube formation of

REDV-TAT-NLS-H12/pZNF580 complexes treated group

b Protonation of oligohistidine beneficial for endosomal escape:

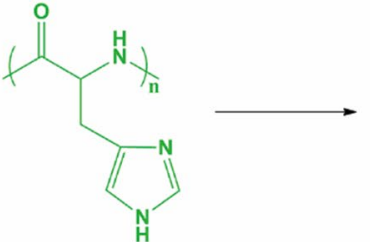

Physiological condition

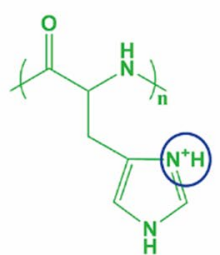

Acid condition

Fig. 1 a Preparation process of REDV-TAT-NLS- $H_{n} /$ pZNF580 complexes and the illustration of gene delivery to ECs mediated by REDV-TAT-NLS-H ${ }_{n}$ ' pZNF580 complexes. b Protonation of oligohistidine beneficial for endosomal escape 
Co., Ltd. (Beijing, China). BCA protein assay kit was obtained from Solarbio Science and Technology Co., Ltd. (Beijing, China). Rabbit anti-human ZNF580 polyclonal antibody, goat anti-rabbit IgG, amiloride hydrochloride, mouse anti-CD31 antibody and goat anti-mouse IgG H\&L secondary antibody (Alexa Fluor ${ }^{\circledR}$ 594) were purchased from Abcam Ltd. (Shanghai, China). Rabbit anti-beta-actin antibody was obtained from Beijing Biosynthesis Biotechnology Co., Ltd. (Beijing, China). Cy5 labeled oligonucleotide (Cy5-oligonucleotide) was purchased from Sangon Biotech Co., Ltd. (Shanghai, China). LysoTracker Green DND-26 and Hoechst 33342 were obtained from Shanghai Invitrogen Biotechnology Co., Ltd. (Shanghai, China). Chlorpromazine hydrochloride was purchased from Sigma-Aldrich (St. Louis, USA). Filipin III was purchased from Cayman Chemical (Michigan, USA). Human umbilical vein endothelial cells (HUVECs) were obtained from the Cell Bank of Typical Culture Collection of Chinese Academy of Sciences (Shanghai, China). The pZNF580-ZNF580 plasmid (pZNF580), smooth muscle cells (SMCs) and male mice were preserved by department of physiology and pathophysiology, Logistics University of Chinese People's Armed Police Force.

\section{Preparation and characterization of complexes Preparation of REDV-TAT-NLS- $\mathrm{H}_{\mathrm{n}} / \mathrm{pZNF580 \text {complexes }}$}

The pZNF580 plasmid was diluted to $50 \mu \mathrm{g} \mathrm{mL}$ with PBS $(\mathrm{pH}=7.4)$ buffer. The REDV-TAT-NLS-H ${ }_{\mathrm{n}}$ / pZNF580 complexes were prepared by mixing REDVTAT-NLS- $\mathrm{H}_{\mathrm{n}}$ solution $\left(0.5 \mathrm{mg} \mathrm{mL} \mathrm{m}^{-1}\right)$ and plasmid solution with various weight ratios ranging from 0.5 to 5 . The gene complex solutions were stirred for $30 \mathrm{~min}$ at room temperature and used for following experiments.

\section{Particle size and zeta potential measurements}

The average particle size and zeta potential of REDVTAT-NLS- $\mathrm{H}_{\mathrm{n}}$ and REDV-TAT-NLS- $\mathrm{H}_{\mathrm{n}} / \mathrm{pZNF580}$ complexes were measured using a Zetasizer Nano ZS (Malvern Instrument, Inc., Worcestershire, UK) with a constant angle of $173^{\circ}$.

\section{Hemolysis assay}

The hemocompatibility of peptide solutions were measured by hemolysis assay. Firstly, fresh whole blood was collected into heparin sodium vacuum blood collection tubes and centrifuged at $3000 \mathrm{rpm}$ for $5 \mathrm{~min}$. After washing, the red blood cells (RBCs) were suspended in $0.01 \mathrm{M}$ PBS $(\mathrm{pH}=7.4)$. Various REDV-TAT-NLS- $\mathrm{H}_{\mathrm{n}}$ solutions $(1000 \mu \mathrm{L})$ were added to the RBCs solution $(25 \mu \mathrm{L})$ and incubated for $24 \mathrm{~h}$. PBS $(\mathrm{pH}=7.4)$ and purified water were used as negative and positive control, respectively.
The absorbance of supernatant was measured at $540 \mathrm{~nm}$. The hemolysis values of REDV-TAT-NLS- $\mathrm{H}_{n}$ solutions were calculated by the following equation:

$$
\text { Hemolysis }(\%)=\frac{O D_{p}-O D_{n c}}{O D_{p c}-O D_{n c}} \times 100 \%
$$

where the $\mathrm{OD}_{\mathrm{p}}$ is the absorbance of REDV-TAT-NLS$\mathrm{H}_{\mathrm{n}}$ solution samples, the $\mathrm{OD}_{\mathrm{pc}}$ is the absorbance of positive control, and the $\mathrm{OD}_{\mathrm{nc}}$ is the absorbance of negative control.

\section{Agarose gel electrophoresis}

The condensing ability of different pZNF580 complexes was evaluated by agarose gel electrophoresis assay. Briefly, the gene complexes were mixed with $6 \times$ loading buffer and electrophoresed on the $0.8 \%$ agarose gel containing $5 \mu \mathrm{L}$ GoldView with $1 \times$ TAE buffer at $120 \mathrm{~V}$ for 25 min. Naked DNA was used as control. A UV illuminator was used to visualize the location of DNA bonds.

\section{Cell culture}

Human umbilical vein endothelial cells (HUVECs) and human umbilical artery smooth muscle cells (HUASMCs) were, respectively plated in cell culture flasks and incubated with DMEM containing 10\% FBS at $37{ }^{\circ} \mathrm{C}$ in humidified atmosphere with $5 \% \mathrm{CO}_{2}$. The cells were cultured to reach $80-90 \%$ confluence before use.

\section{In vitro cytotoxicity}

The cytotoxicity of REDV-TAT-NLS- $\mathrm{H}_{\mathrm{n}}$ and REDV-TATNLS- $\mathrm{H}_{\mathrm{n}} / \mathrm{pZNF580}$ complexes for HUVECs was evaluated by MTT assay. Briefly, cells $\left(1 \times 10^{4}\right.$ cells/well $)$ were plated in 96-well plate and cultured in DMEM containing $10 \%$ FBS for $24 \mathrm{~h}$ to achieve $80 \%$ confluence. Then the medium was removed and serum-free medium was added to each well and cultured overnight. After that, various REDV-TAT-NLS- $\mathrm{H}_{\mathrm{n}}$ solutions and pZNF580 complexes at various concentrations ranging from 5 to $120 \mu \mathrm{g} \mathrm{mL}{ }^{-1}$ were added and incubated for $48 \mathrm{~h}$. Then, MTT reagent $\left(20 \mu \mathrm{L}, 5 \mathrm{mg} \mathrm{mL} \mathrm{m}^{-1}\right)$ was added to each well and cultured for another $4 \mathrm{~h}$ to form formazan crystals. Then, the medium was removed, followed by adding $150 \mu \mathrm{L}$ DMSO to dissolve the formazan crystals. The optical density was measured at $490 \mathrm{~nm}$ using a microplate reader (BIO-RAD, iMark ${ }^{\mathrm{TM}}$, USA). The relative cell viability was calculated as: relative cell viability $(\%)=\left(\mathrm{OD} 490_{(\text {sample) }} / \mathrm{OD} 490_{(\text {control })}\right) \times 100 \%$, where OD490 (sample) represents the absorbance value of experimental wells minus zero wells, and OD490 (control) represents the absorbance value of untreated cell wells minus zero wells). 


\section{In vitro transfection}

The transfection efficiency of REDV-TAT-NLS- $\mathrm{H}_{\mathrm{n}} /$ pZNF580 complexes was evaluated by HUVECs and HUASMCs. In brief, HUVECs and HUASMCs were seeded in 24-well plates at a density of $1 \times 10^{5}$ cells per well and cultured with DMEM containing 10\% FBS until 70-80\% confluence. Before transfection, the cells were starved with serum-free medium for $12 \mathrm{~h}$. REDV-TATNLS-H ${ }_{n} /$ ZZNF580 complexes were added into each well (3 $\mu \mathrm{g}$ pZNF580 per well). After $4 \mathrm{~h}$ incubation, the medium was replaced with fresh DMEM containing $10 \%$ FBS and the cells were cultured for another $24 \mathrm{~h}$ in $\mathrm{CO}_{2}$ incubator. To detect the expression of pZNF580, green fluorescent protein was observed via an inverted fluorescent microscope (Fluorescence OLYMPUS U-RFLT50, microscopy Olympus DP72) at $24 \mathrm{~h}$ point.

\section{Cell migration assay}

Wound healing assay was performed to investigate the migration ability of transfected HUVECs by various REDV-TAT-NLS-H $\mathrm{n}_{\mathrm{n}}$ pZNF580 complexes. HUVECs were seeded in a 24-well plate and transfected with various REDV-TAT-NLS- $\mathrm{H}_{\mathrm{n}} / \mathrm{pZNF580}$ complexes, respectively. After a $24 \mathrm{~h}$ culture, a straight line was scratched across each well using a $200 \mu \mathrm{L}$ micropipettor tip. The wells were washed twice with D-Hanks and cultured at $37^{\circ} \mathrm{C}$. The images of cell migration were obtained with an inverted microscope at 0,6 and $12 \mathrm{~h}$. The relative recovered area was calculated using Image J software with the following equation.

$$
\text { Relative recovered area }(\%)=\frac{\text { Recovered area }}{\text { Wounded area }} \times 100 \%
$$

The migration ability of the transfected cells was also evaluated using transwell chambers with $8.0 \mu \mathrm{m}$ pore sized, gelatinized polycarbonate membrane. The upper transwell chambers were pre-treated with serum-free medium at $37{ }^{\circ} \mathrm{C}$ with $5 \% \mathrm{CO}_{2}$ in incubator for $2 \mathrm{~h}$. The transfected cells were starved with serum-free medium for $12 \mathrm{~h}$, and then seeded in the upper transwell chambers $\left(1.2 \times 10^{5}\right.$ cells per well). At the same time, the lower transwell chambers were added with fresh medium containing $10 \%$ FBS, followed by incubating the transwell system for $6 \mathrm{~h}$. The upper chambers were washed twice with $0.01 \mathrm{M}$ PBS ( $\mathrm{pH}=7.4)$ and fixed with $4 \%$ paraformaldehyde/PBS $(\mathrm{pH}=7.4)$ at room temperature for $10 \mathrm{~min}$. Sterilized cotton swabs were used to remove the cells inside the chambers that didn't pass through the $8.0 \mu \mathrm{m}$ pore. The cells on the lower surface of the upper chambers were stained with eosin at $37^{\circ} \mathrm{C}$ for $8 \mathrm{~min}$. Migrating cells were observed under an inverted fluorescent microscope, and the number of migrated cells was counted by Image-Pro Plus 6.0 software.

\section{Capillary-like tube formation}

The formation ability of capillary-like tube structure was evaluated by HUVECs in vitro. Matrigel was dissolved at $4{ }^{\circ} \mathrm{C}$ overnight, then each well of the pre-cooling 96-well plate was coated with $50 \mu \mathrm{L}$ growth factor-reduced Matrigel, and followed by incubation at $37{ }^{\circ} \mathrm{C}$ for $1 \mathrm{~h}$. Subsequently, HUVECs were transfected with various REDV-TAT-NLS-H $/$ pZNF580 complexes. The transfected cells were trypsinized and seeded on the Matrigel $\left(4 \times 10^{4}\right.$ cells per well), followed by being cultured for $6 \mathrm{~h}$. The cells treated with pZNF580 were used as the negative control. Images of the formation of capillary-like structure at five randomly fields were obtained by using a microscope. The number of the formed tubes in each image was counted manually.

\section{Western blot analysis}

HUVECs were plated on a 6-well plate and transfected with REDV-TAT-NLS- $\mathrm{H}_{\mathrm{n}} / \mathrm{pZNF580}$ complexes for $24 \mathrm{~h}$. The transfected cells were washed three times with cold 0.01 M PBS ( $\mathrm{pH}=7.4)$, and followed by extracting the total protein with RIPA lysis buffer containing $1 \%$ volume of PMSF. After $30 \mathrm{~min}$ on ice, the lysates were centrifuged at $12,000 \mathrm{rpm}$ at $4{ }^{\circ} \mathrm{C}$ for $10 \mathrm{~min}$. The total protein was quantified by BCA protein assay kit and denatured by adding $5 \times$ SDS. The same amount of each sample (approximately $80 \mu \mathrm{g}$ protein) was loaded into each lane, separated by $10 \%$ polyacrylamide SDS-PAGE gel and transferred onto polyvinylidene difluoride (PVDF) membranes. The membranes were cultured with $8 \%$ defat milk in TBST for $1 \mathrm{~h}$ and incubated with rabbit anti-ZNF580 polyclonal antibody in TBST overnight. Thereafter, blots were incubated with horseradish peroxidase conjugated anti-rabbit secondary antibody for $1 \mathrm{~h}$ and washed twice with TBST. Protein bands were developed by a standard enhanced chemiluminescence (ECL) kit, and observed via a gel image analysis system.

\section{Quantitative real-time PCR assay}

HUVECs were treated with various REDV-TAT-NLS$\mathrm{H}_{\mathrm{n}} / \mathrm{pZNF580}$ complexes and cultured in an incubator. The cells which were treated with pZNF580 were used as a negative control. After $24 \mathrm{~h}$ transfection, the total RNA was extracted from cells with TRIzol reagent, and reverse-transcribed into cDNA using TransScript First-Strand cDNA Synthesis SuperMix. The resulting cDNAs were used as templates for quantitative real-time PCR using TransStart ${ }^{\mathrm{TM}}$ Top Green qPCR SuperMix, and detected with a SYBR Green on ABI 7300 stepone sequence detection PCR system (Applied Biosystems). The PCR primer sequences of ZNF580 were as follows: ZNF580 forward 5'-AAAAAGCTTGTGGAGGCGCACGTGCTG-3' ${ }^{\prime}$, and ZNF580 reverse 
5'-AAAAAGATCTTGCCCGGAGTGCGCCCGTG-3' . The expression of glyceraldehyde-3-phosphate dehydrogenase (GAPDH) was used as an internal control. The forward and reverse primer sequences of GAPDH were 5'-AGGTGAAGGTCGGAGTCAAC-3', 5'-CGCTCCTGGAAGATGGTGAT-3', respectively. The results were analyzed using StepOne software v2.1.

\section{Cellular uptake and confocal laser scanning microscopy (CLSM) assay}

The cellular uptake and mean fluorescence intensity (MFI) in HUVECs were quantitatively evaluated by a flow cytometry. Cy5-oligonucleotide was mixed with unlabeled oligonucleotide at a 1:1 ratio. Cells were seeded into 6-well plates at $3 \times 10^{5}$ cells per well and transfected with various REDV-TAT-NLS- $\mathrm{H}_{\mathrm{n}} / \mathrm{Cy} 5$-oligonucleotide complexes. After $4 \mathrm{~h}$ incubation, cells were washed three times with $0.01 \mathrm{M}$ PBS $(\mathrm{pH}=7.4)$ and trypsinized with $0.25 \%$ trypsin. Subsequently, the cells were centrifuged, collected and re-suspended in $300 \mu \mathrm{L} \mathrm{PBS}(\mathrm{pH}=7.4)$, followed by analyzing with a flow cytometer (Beckman MoFlo XDP, USA). HUASMCs treated with REDV-TAT$\mathrm{NLS}-\mathrm{H}_{12} / \mathrm{Cy} 5$-oligonucleotide complexes was used as a control group.

CLSM was used to visually observe the intracellular distribution of different REDV-TAT-NLS- $\mathrm{H}_{\mathrm{n}} /$ Cy5-oligonucleotide complexes. For live-cell imaging, cells were seeded in a confocal dish with a density of $1 \times 10^{5}$ cells and cultured for $24 \mathrm{~h}$. Thereafter, cells were transfected by various REDV-TAT-NLS- $\mathrm{H}_{\mathrm{n}} / \mathrm{Cy} 5-$ oligonucleotide complexes as described above. After $24 \mathrm{~h}$ incubation, the cells were washed twice with PBS $(\mathrm{pH}=7.4)$. The lysosomes of HUVECs were stained with the $\mathrm{pH}$ sensitive dye LysoTracker Green (DND26, Life Technologies) at $75 \mathrm{nM}$ for $1 \mathrm{~h}$, and nuclei were stained with Hoechst 33342 for $20 \mathrm{~min}$. Then, the cells were washed twice with PBS $(\mathrm{pH}=7.4)$ and observed by CLSM (Olympus FV1000, Japan) at excitation wavelengths of 649,504 and $350 \mathrm{~nm}$ for Cy5 (red), LysoTracker Green (green) and Hoechst 33342 (blue), respectively. The co-localization rate (CLR) was calculated by Image-Pro Plus 6.0 software according to the following equation.

\section{Co-localization ratio

$$
=\frac{\text { Number of yellow or pink pixels }}{\text { Number of yellow, red and pink pixels }} \times 100 \%
$$

where red corresponds to the Cy5-oligonucleotide in cytoplasm, yellow corresponds to the Cy5-oligonucleotide in endosome/lysosomes, and pink corresponds to the Cy5-oligonucleotide in nucleus.

\section{Cellular uptake mechanism}

To further elucidate the cellular uptake mechanism of REDV-TAT-NLS- $\mathrm{H}_{\mathrm{n}} / \mathrm{Cy} 5$-oligonucleotide complexes, HUVECs were pretreated with different inhibitors before transfection [53]. Briefly, cells were seeded onto the 6-well plates and cultured as described above. To probe the cellular uptake mechanism of REDV-TAT-NLS- $\mathrm{H}_{\mathrm{n}} /$ Cy5-oligonucleotide complexes, the cells were pretreated in DMEM with various endocytic inhibitors including chlorpromazine $(30 \mu \mathrm{M})$, amiloride hydrochloride $(30 \mu \mathrm{M})$ and filipin III $\left(5 \mu \mathrm{g} \mathrm{mL}{ }^{-1}\right)$ at $37^{\circ} \mathrm{C}$ for $1 \mathrm{~h}$, which were used to inhibit the clathrin-mediated endocytosis, micropinocytosis and caveolae-mediated endocytosis, respectively. REDV peptide was also used to pretreat the cells and cultured for $1 \mathrm{~h}$ before transfection in order to evaluate the REDV function in endocytic pathway. The REDV-TAT-NLS- $\mathrm{H}_{12} / \mathrm{Cy} 5$-oligonucleotide complexes were added into each well for $4 \mathrm{~h}$ incubation. Subsequently, cells were washed three times with $0.01 \mathrm{M}$ PBS $(\mathrm{pH}=7.4)$ followed by trypsinization and centrifugation. Cells were then re-suspended in $300 \mu \mathrm{L}$ PBS $(\mathrm{pH}=7.4)$ and analyzed by a flow cytometry (Beckman MoFlo XDP, USA).

\section{In vivo angiogenesis assay}

To evaluate the angiogenesis ability of the transfected HUVECs by REDV-TAT-NLS- $\mathrm{H}_{\mathrm{n}} / \mathrm{pZNF}$ 80 complexes, in vivo angiogenesis assay was performed as previously described [51]. Male mice (6 weeks old, 20-25 g) were used as an animal experimental model. HUVECs were pretreated with different REDV-TAT-NLS- $\mathrm{H}_{\mathrm{n}} / \mathrm{pZNF}$ Z80 complexes for $4 \mathrm{~h}$ and cultured for another $24 \mathrm{~h}$. Then the transfected cells were trypsinized with $0.25 \%$ trypsin and mixed with $800 \mu \mathrm{L}$ matrigel at a final concentration of $1 \times 10^{6}$ cells $\mathrm{mL}^{-1}$. Before surgery, male mice were treated with chloral hydrate $(300 \mathrm{mg} / \mathrm{kg})$ for anesthesia. The mixture was subcutaneously injected in mice using a $1 \mathrm{~mL}$ syringe with a 25 -gauge needle. Four days later, the mice were injected with excess chloral hydrate to euthanasia. Matrigel implants were removed, fixed with formalin, embedded in paraffin, and sliced into thick sections. Then the sections were stained with hematoxylin and eosin $(H \& E)$ and the luminal structures were observed using a microscope. In addition, the sections were immunohistochemically stained with mouse antiCD31 antibody [diluted in PBS $(\mathrm{pH}=7.4)$ at $1: 20$ ] for $60 \mathrm{~min}$ and followed with goat anti-mouse IgG H\&L secondary antibody (Alexa Fluor ${ }^{\circledR}$ 594). The cell nuclei were stained with DAPI. Immunohistochemically stained sections were used to further determine the formation of microvessel structure which was observed by a fluorescence microscope for each section. 
Male mice were preserved by Department of Physiology and Pathophysiology, Logistics University of Chinese People's Armed Police Force and hosted in SPF room of animal house. All animals were treated following the protocol approved by Armed Police Logistics College and conformed to the "Guide for the protection and use of experimental animals" of the American National Institutes of Health.

\section{Statistical analysis}

All statistical analyses were performed with the one-way ANOVA with a $\mathrm{P}<0.05$ being considered significant.

\section{Results}

Particle size and zeta potential of REDV-TAT-NLS- $\mathrm{H}_{\mathbf{n}}$ micelles and their gene complexes

Suitable particle size and surface charge of micelles are beneficial for effective cellular uptake and endocytosis. The size and zeta potential of REDV-TAT-NLS- $\mathrm{H}_{\mathrm{n}}$ micelles (Table 1) and their pZNF580 complexes with various $\mathrm{w} / \mathrm{w}$ ratios ranging from 1 to 5 were measured by a Zetasizer Nano ZS (Fig. 3). The REDV-TAT-NLS$\mathrm{H}_{\mathrm{n}}$ micelles showed narrower size distribution than their pZNF580 complexes as demonstrated by dynamic light scattering (DLS) curves (Additional file 1: Figure S1-S6). The REDV-TAT-NLS- $\mathrm{H}_{0}$ micelles (about $228 \mathrm{~nm})$ were much larger than REDV-TAT-NLS- $\mathrm{H}_{\mathrm{n}}$ $(\mathrm{n}=4,8,12)$ micelles $(<200 \mathrm{~nm})$. Because $\mathrm{H}$ residue was hydrophobic at physiological condition, the amphiphilic REDV-TAT-NLS- $H_{n}$ peptides could form stable micelles with relatively compact structure compared with REDV-TAT-NLS- $\mathrm{H}_{0}$. The surface charge of these micelles was positive, which was suitable for condensing pZNF580. Moreover, there was no significant distinction in zeta potential of these micelles with different lengths of $H_{n}$ sequence because $H_{n}$ preferentially formed the hydrophobic core of these stable micelles. As shown in Fig. 2(1), the size of REDV-TAT-NLS- $\mathrm{H}_{\mathrm{n}}$ /pZNF580 complexes ranged from 117 to $288 \mathrm{~nm}$, which was suitable for cellular uptake. Furthermore, the zeta potential of the REDV-TAT-NLS- $\mathrm{H}_{\mathrm{n}} / \mathrm{pZNF580}$ complexes increased with increasing $\mathrm{w} / \mathrm{w}$ ratios from 1 to 5 . For

Table 1 Size and zeta potential of REDV-TAT-NLS- $H_{n}$ micelles

\begin{tabular}{|c|c|c|c|}
\hline Sample ID & Size $(n m)$ & $P D I$ & Zeta potential $(\mathrm{mV})$ \\
\hline REDV-TAT-NLS-H ${ }_{0}$ & $228.1 \pm 5.3$ & $0.30 \pm 0.04$ & $27.8 \pm 1.8$ \\
\hline REDV-TAT-NLS- ${ }_{4}$ & $142.3 \pm 4.3$ & $0.32 \pm 0.02$ & $25.8 \pm 1.7$ \\
\hline REDV-TAT-NLS- $H_{8}$ & $151.7 \pm 2.5$ & $0.30 \pm 0.03$ & $26.7 \pm 0.4$ \\
\hline REDV-TAT-NLS-H 12 & $136.6 \pm 1.7$ & $0.24 \pm 0.06$ & $26.3 \pm 0.3$ \\
\hline
\end{tabular}

$P D /$ polydispersity index
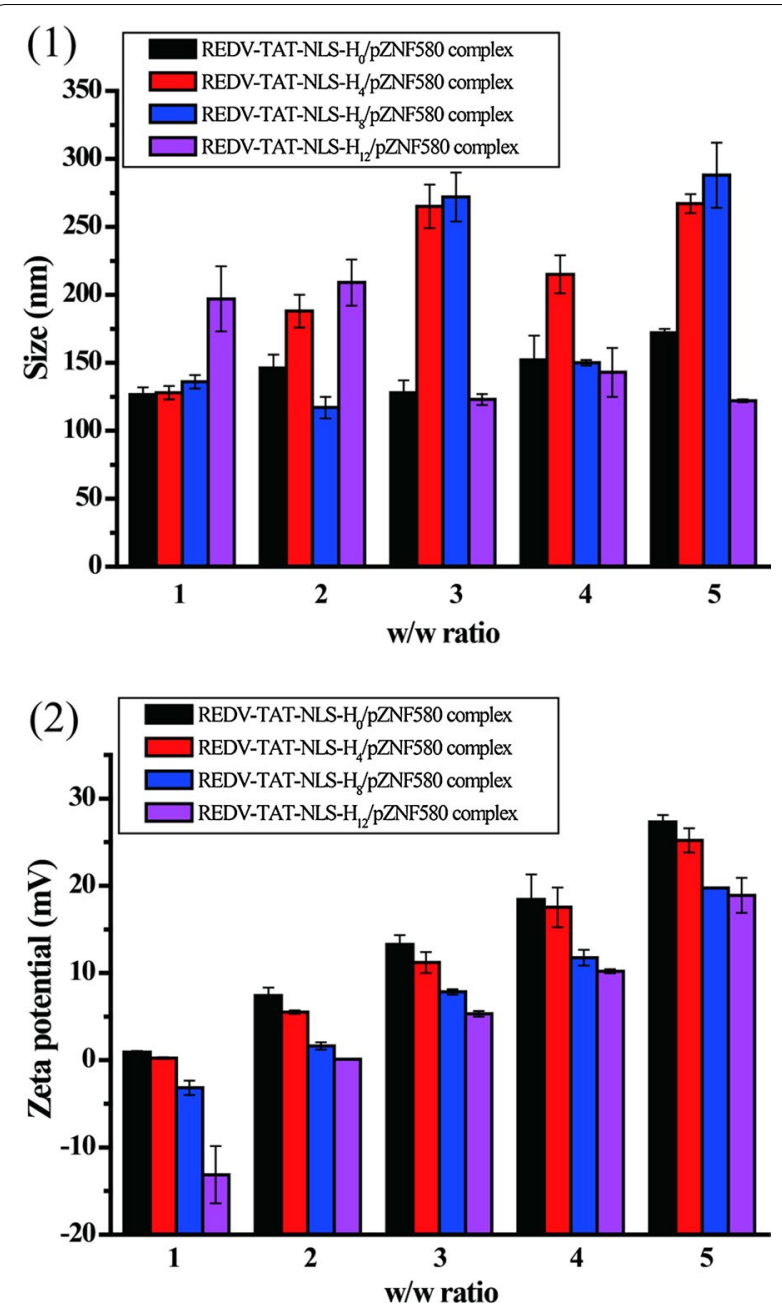

Fig. 2 Size and zeta potential of REDV-TAT-NLS-H ${ }_{n} /$ pZNF580 complexes at various $\mathrm{w} / \mathrm{w}$ ratios $\left(1,2,3,4\right.$ and 5) of REDV-TAT-NLS-H $\mathrm{H}_{n}$ and pZNF580. (1) Diameter of the REDV-TAT-NLS- $H_{n} /$ pZNF580 complexes, (2) Zeta potential of the REDV-TAT-NLS- $H_{n} /$ pZNF580 complexes

REDV-TAT-NLS- $\mathrm{H}_{0} / \mathrm{pZNF580} \mathrm{complexes} \mathrm{and} \mathrm{REDV-}$ TAT-NLS- $\mathrm{H}_{4} /$ pZNF580 complexes, their zeta potential was positive when the $\mathrm{w} / \mathrm{w}$ ratio was 1 , while this ratio must be higher than 2 for REDV-TAT-NLS- $\mathrm{H}_{12} /$ pZNF580 complexes. At the same $w / w$ ratio, the zeta potential of REDV-TAT-NLS- $\mathrm{H}_{\mathrm{n}} /$ pZNF580 complexes decreased with increasing the $n$ number of $H_{n}$ in peptide sequences. This decrease tendency is mainly attributed to the hydrophobic character of $\mathrm{H}_{\mathrm{n}}$ sequence at physiological condition ( $\mathrm{pH}=7.4) . \mathrm{H}_{\mathrm{n}}$ sequence did not induce to further high positive charge [54]. The zeta potential of REDV-TAT-NLS- $\mathrm{H}_{\mathrm{n}} / \mathrm{pZNF580}$ complexes could be mediated by altering the weight ratio of REDV-TATNLS- $\mathrm{H}_{n}$ peptides and pZNF580, and the sizes of these complexes were less than $300 \mathrm{~nm}$, which were beneficial for endocytosis. 

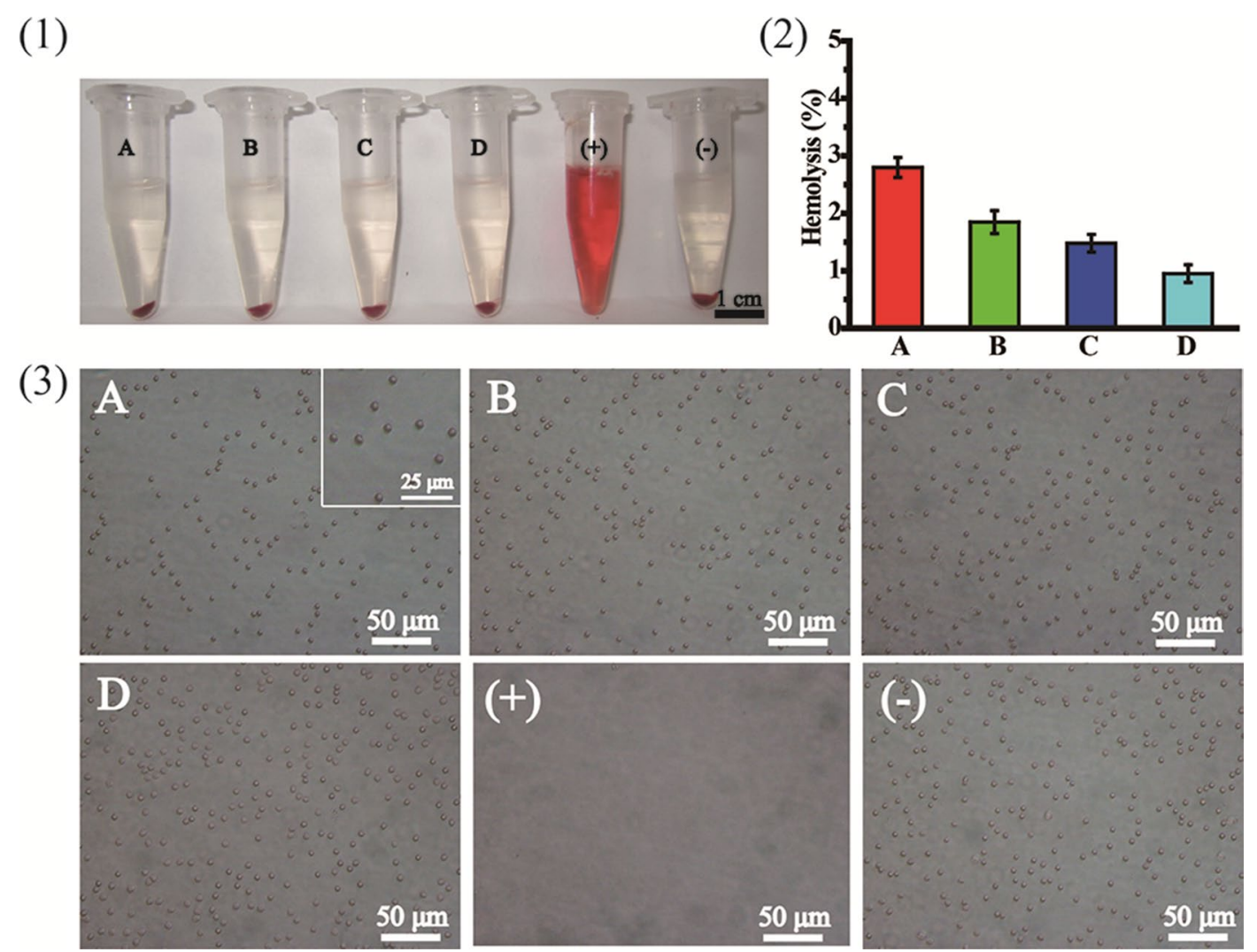

Fig. 3 Photographs of the anti-hemolytic activity of REDV-TAT-NLS- $\mathrm{H}_{\mathrm{n}}$ solution after $24 \mathrm{~h}$ incubation (1), hemolytic index (2), images of RBCs in

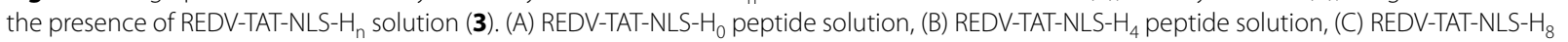
peptide solution, (D) REDV-TAT-NLS-H 12 peptide solution, (+) purified water and (-) PBS

\section{Hemocompatibility of REDV-TAT-NLS- $\mathrm{H}_{\mathrm{n}}$ peptides}

The hemocompatibility of gene carriers is very important for their in vivo application. To evaluate the hemocompatibility of REDV-TAT-NLS- $\mathrm{H}_{\mathrm{n}}$ peptides, hemolytic activity and RBC aggregation assay were performed in vitro [55]. $\mathrm{RBCs}$ treated with PBS $(\mathrm{pH}=7.4)$ and purified water were used as the negative and positive controls, respectively. As shown in Fig. 3(1), (2), the hemolytic index of REDV-TAT-NLS- $\mathrm{H}_{\mathrm{n}}$ peptides decreased with increasing $\mathrm{H}_{\mathrm{n}}$ sequence length. All peptide micelles showed lower hemolysis than standard criteria (5\%). According to ISO 10993-4, they can be considered as feasible blood-contacting biomaterials. In addition, the RBC aggregation results also showed that more RBCs remained unchanged when the n number of $H_{n}$ sequences increased from 4 to 12 (Fig. 3(3)). These REDV-TAT-NLS- $\mathrm{H}_{\mathrm{n}}$ peptides exhibited good hemocompatibility.

\section{pDNA binding ability of REDV-TAT-NLS- $\mathrm{H}_{\mathrm{n}}$ peptides}

It is well known that DNA binding ability induced by electrostatic interaction is a prerequisite for gene carriers. REDV-TAT-NLS- $\mathrm{H}_{0}$, REDV-TAT-NLS- $\mathrm{H}_{4}$, REDV-TAT-NLS- $\mathrm{H}_{8}$ and REDV-TAT-NLS- $\mathrm{H}_{12}$ peptides are positively charged in physiological condition. In this study, the binding and condensing ability of REDVTAT-NLS- $\mathrm{H}_{\mathrm{n}} / \mathrm{pZNF580}$ complexes with the $\mathrm{w} / \mathrm{w}$ ratios ranging from 0.5 to 5 was evaluated by agarose gel electrophoresis. The REDV-TAT-NLS- $\mathrm{H}_{\mathrm{n}} / \mathrm{pZNF580} \mathrm{com-}$ plexes were prepared by mixing peptides with pZNF580, and incubated for $30 \mathrm{~min}$. As shown in Fig. 4, the REDVTAT-NLS- $\mathrm{H}_{0}$, REDV-TAT-NLS-H${ }_{4}$, REDV-TAT-NLS- $\mathrm{H}_{8}$ and REDV-TAT-NLS- $\mathrm{H}_{12}$ peptides were able to completely retard the mobility of pZNF580 at the $\mathrm{w} / \mathrm{w}$ ratios of 2, 2, 2 and 3, respectively. Obviously, the condensing pZNF580 ability of these peptides decreased when $\mathrm{H}_{\mathrm{n}}$ sequence increased from 4 to 12 . This trend was consistent with the zeta potential results. In a word, all of these peptides showed strong pZNF580 condensing ability. It's well known that highly positive zeta potential is necessary for gene carriers to condense and deliver DNA efficiently. Therefore, the $\mathrm{w} / \mathrm{w}$ ratio of 5 was chosen for the following studies. 

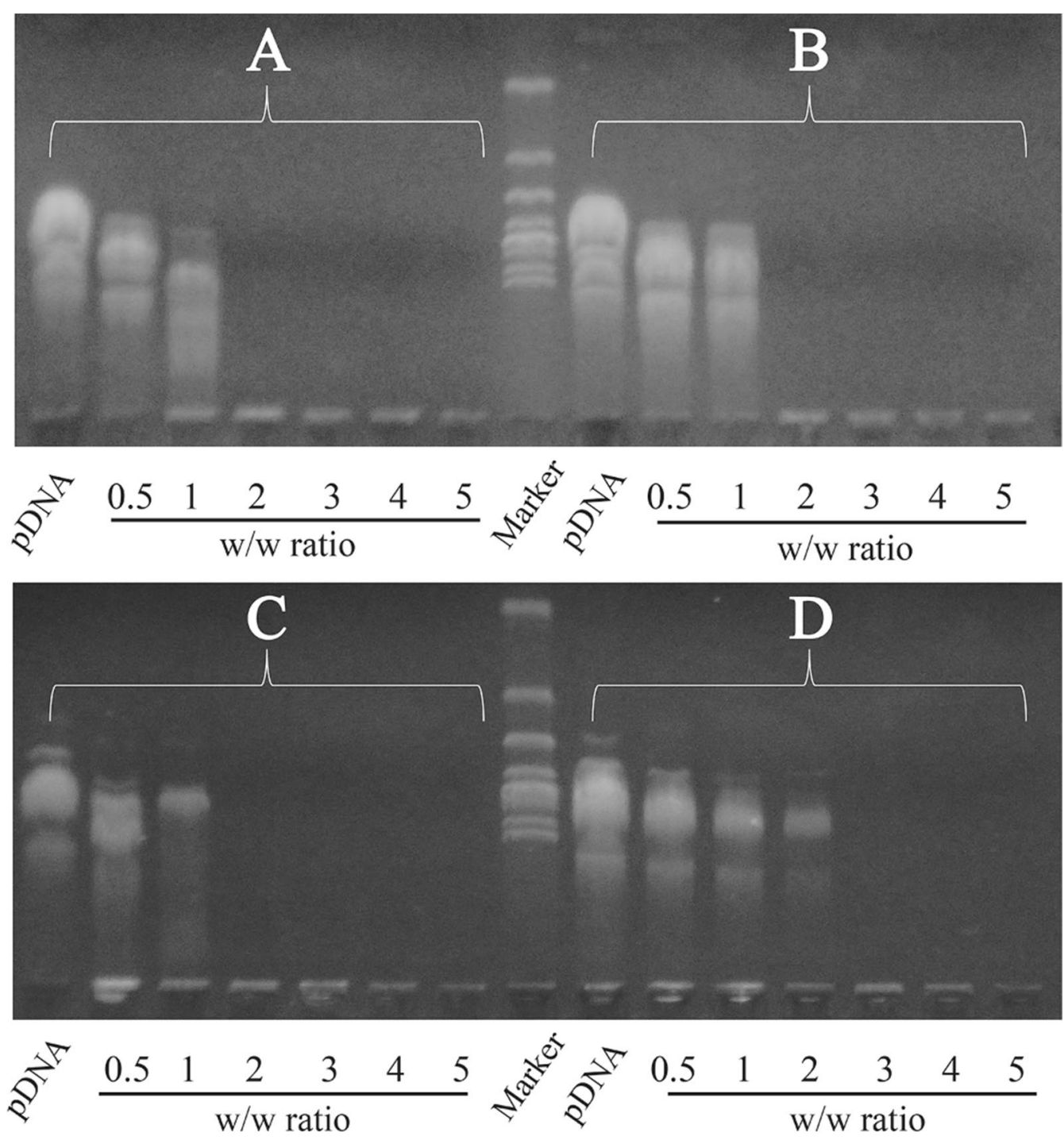

Fig. 4 Agarose gel electrophoresis of various REDV-TAT-NLS-H $/$ /pZNF580 complexes at different w/w ratios varying from 0.5 to 5: (A) REDV-TAT-

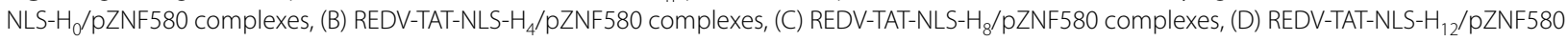
complexes

\section{In vitro cytotoxicity}

The cytotoxicity of gene carriers is a critical factor for their future application in vivo. The in vitro relative cell viability of REDV-TAT-NLS- $\mathrm{H}_{\mathrm{n}}$ and REDV-TATNLS- $\mathrm{H}_{\mathrm{n}} / \mathrm{pZNF580}$ complexes was evaluated by MTT assay. The concentration of peptides ranged from 5 to $120 \mu \mathrm{g} \mathrm{mL}^{-1}$. As shown in Fig. 5, no significant cytotoxicity was observed in all peptide groups. With the increase of concentration, the relative cell viability did not decrease obviously. At the same concentration, compared with REDV-TAT-NLS- $\mathrm{H}_{\mathrm{n}}(\mathrm{n}=4,8$ and 12) micelles, the REDV-TAT-NLS- $\mathrm{H}_{\mathrm{n}} / \mathrm{pZNF580}$ complexes showed relatively high cell viability. Moreover, all groups exhibited very low cytotoxicity and their relative cell viabilities were higher than $80 \%$ at the concentration of $120 \mathrm{mg} \mathrm{mL}^{-1}$. These results indicated that these REDVTAT-NLS-H $\mathrm{H}_{\mathrm{n}}(\mathrm{n}=4,8,12)$ peptides would be safe as a gene carrier.

\section{In vitro transfection}

In order to investigate the influence of introducing $\mathrm{H}_{n}$ sequence into gene carriers on gene delivery, HUVECs were transfected by different REDV-TAT-NLS- $\mathrm{H}_{\mathrm{n}}$ / pZNF580 complexes in vitro. The HUVECs transfected with REDV-TAT-NLS- $\mathrm{H}_{0} /$ pZNF580 complexes and naked pZNF580 gene were used as positive and negative 


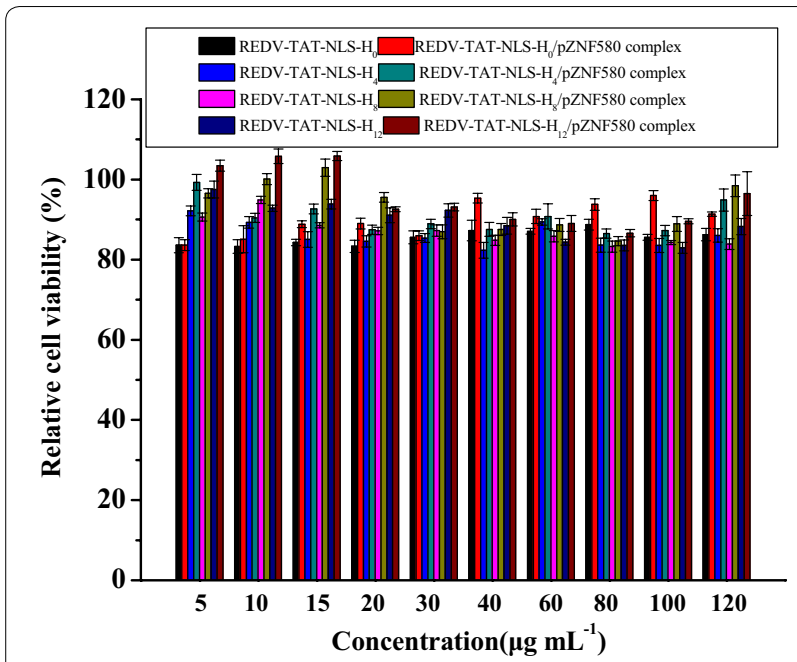

Fig. 5 Relative cell viability of HUVECs after $48 \mathrm{~h}$ in the presence of different REDV-TAT-NLS- $H_{n}$ or REDV-TAT-NLS- $H_{n} /$ pZNF580 complexes with peptide concentration ranging from 5 to $120 \mu \mathrm{gL}^{-1}$ at $\mathrm{W} / \mathrm{W}$ ratio of 5 (mean $\pm S D, n=3$ )

controls, respectively. As illustrated in Fig. 6, all REDVTAT-NLS- $\mathrm{H}_{\mathrm{n}} / \mathrm{pZNF580}$ complexes groups showed green fluorescence protein, implying efficient gene delivery and successful pZNF580 expression. Among all groups, REDV-TAT-NLS- $\mathrm{H}_{12}$ /pZNF580 complexes group showed the best transfection result. All REDV-TAT-NLS$\mathrm{H}_{\mathrm{n}} / \mathrm{pZNF580}$ complexes could deliver pZNF580 into cells to express ZNF580 gene. Compared with the PEI-based gene carriers in our previous studies, the transfection efficiency of REDV-TAT-NLS- $\mathrm{H}_{\mathrm{n}} / \mathrm{pZNF580}$ complexes was low, but their cytotoxicity was very low even at high concentration. Because ECs are hard to be transfected by gene complexes [56]. The instability and limited positive charges of the peptide-based gene carriers induced low transfection efficiency. In addition, HUASMCs were treated with REDV-TAT-NLS- $\mathrm{H}_{12} /$ pZNF580 complexes and showed very low transfection, which proved the target function of REDV-TAT-NLS- $\mathrm{H}_{12} /$ pZNF580 complexes for HUVECs.

\section{Cell migration assay}

The migration ability of HUVECs plays an important role in the formation of a confluent EC monolayer for cardiovascular disease treatment. Here, wound healing assay was used to evaluate the migration ability of transfected HUVECs by REDV-TAT-NLS- $\mathrm{H}_{\mathrm{n}}$ /pZNF580 complexes. After $24 \mathrm{~h}$ incubation, an artificial scratch with parallel borders was mechanically created and migration process at different time points was monitored by capturing pictures (Fig. 7(1)). HUVECs treated with REDV-TAT-NLS$\mathrm{H}_{0} /$ pZNF580 complexes and naked pZNF580 gene were used as positive and negative controls, respectively. The migration rate of transfected HUVECs with REDV-TAT$\mathrm{NLS}-\mathrm{H}_{\mathrm{n}}$ /pZNF580 complexes was much higher than the negative control group (Fig. 7). REDV-TAT-NLS- $\mathrm{H}_{12} /$ pZNF580 complexes group showed the highest migration rate $(94.13 \pm 0.43 \%)$. The complexes containing $\mathrm{H}_{\mathrm{n}}$ sequence were beneficial for cell transfection and migration.

In addition, the cell migration ability was also evaluated by transwell chambers. As shown in Fig. 8, REDVTAT-NLS- $\mathrm{H}_{\mathrm{n}} /$ pZNF580 complexes groups showed larger cell migration number than the control group. The cell migration number of REDV-TAT-NLS- $\mathrm{H}_{12}$ /pZNF580 complexes group was the largest among all groups (Fig. 8(D)). The results of transwell migration assay is approximately similar to wound healing assay. REDVTAT-NLS- $\mathrm{H}_{\mathrm{n}} / \mathrm{pZNF580}$ complexes containing long $\mathrm{H}_{\mathrm{n}}$ sequence benefited for high cell migration and proliferation. $\mathrm{H}_{\mathrm{n}}$ sequence can be protonated and help to promote the endosome/lysosome escape via proton sponge effect, which further enhances the transfection efficiency.

\section{In vitro tube formation}

The formation of capillary-like tubes via HUVECs migration toward each other is an integral part of numerous pathologies [57]. Here, angiogenesis assay was used to evaluate the tube formation ability of transfected HUVECs. Without any growth factors, the transfected HUVECs proliferated and migrated on matrigel to form vascular rings (Fig. 9). HUVECs treated with REDV-TATNLS- $\mathrm{H}_{0} / \mathrm{pZNF580} \mathrm{complexes} \mathrm{and} \mathrm{naked} \mathrm{pZNF580} \mathrm{were}$ used as the positive and negative controls, respectively. After $6 \mathrm{~h}$ incubation, tube formation can be observed in all groups. Compared with the negative group, HUVECs treated with REDV-TAT-NLS- $\mathrm{H}_{\mathrm{n}} /$ pZNF580 complexes showed a strong angiogenesis ability, especially the REDV-TAT-NLS- $\mathrm{H}_{12} /$ pZNF580 complexes group with a tube number of nearly 26 (Fig. 9(D)). This group exhibited approximately twofold tubes compared with the positive control (Fig. 9(A)), while REDV-TAT-NLS-H ${ }_{4} /$ pZNF580 complexes and REDV-TAT-NLS- ${ }_{8} /$ pZNF580 complexes groups formed relatively less tubes. These results indicated that REDV-TAT-NLS- $\mathrm{H}_{12} /$ pZNF580 complexes significantly enhanced tube-forming ability. It is owing to longer $\mathrm{H}_{\mathrm{n}}$ sequence feasible to promote gene delivery efficiency. The expression of pZNF580 plasmid in nucleus enhanced the proliferation, migration as well as vascularization of HUVECs.

\section{Western blot analysis}

Western blot analysis is a powerful method to quantitatively analyze the expression of ZNF580 gene in HUVECs. HUVECs was treated with REDV-TAT-NLS- $\mathrm{H}_{0} /$ 


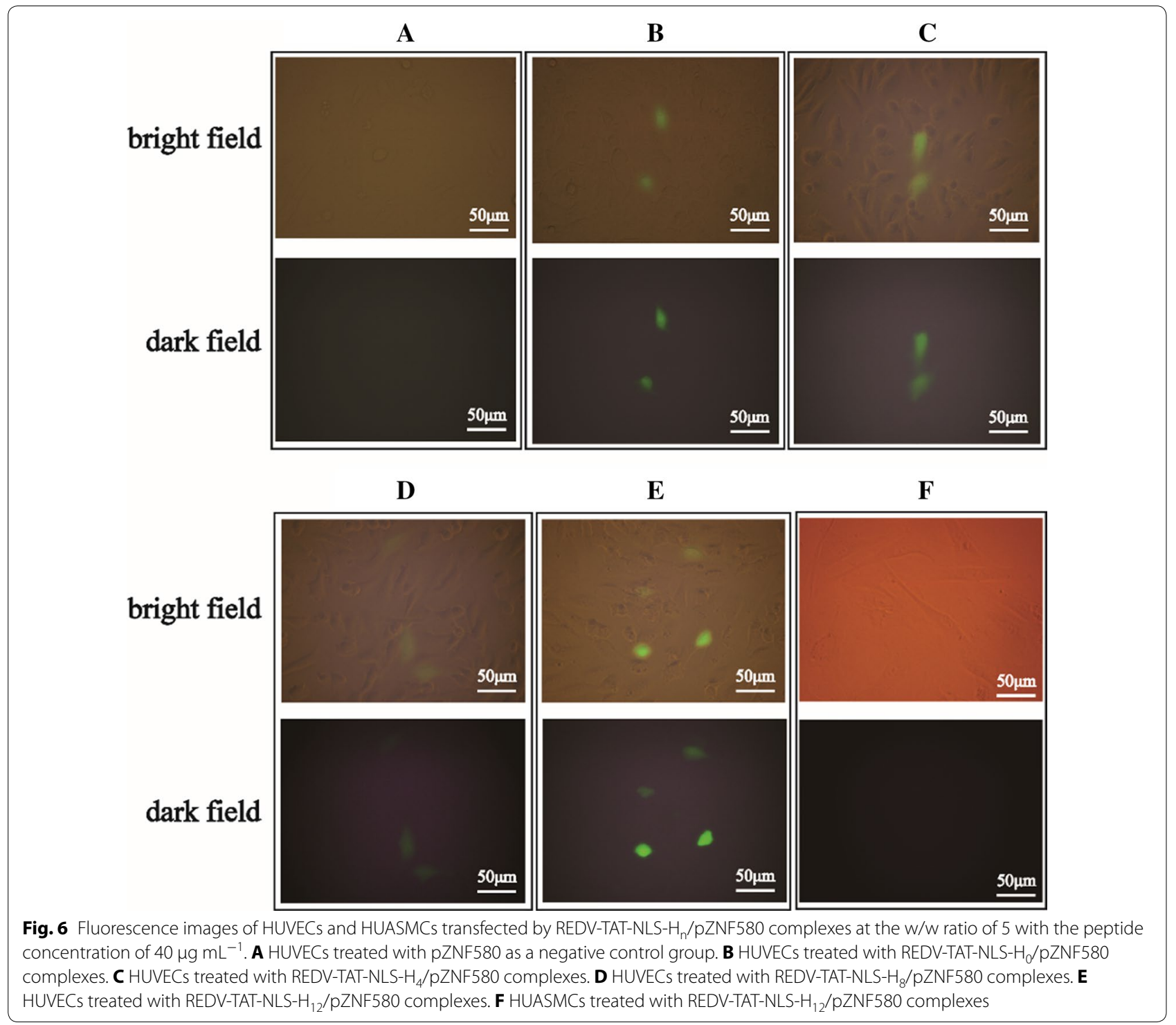

pZNF580 complexes, which was used as a positive group. Relative protein level (\%) was calculated by comparing the protein expression of ZNF580 gene with $\beta$-actin gene. As shown in Fig. 10, compared with REDV-TATNLS- $\mathrm{H}_{0} /$ pZNF580 complexes group, the cells which were treated with REDV-TAT-NLS- $\mathrm{H}_{\mathrm{n}} /$ pZNF580 complexes exhibited higher relative protein level. Cells transfected with REDV-TAT-NLS- $\mathrm{H}_{12}$ /pZNF580 complexes showed a relative protein level of $64.74 \%$, which was the highest protein expression among all groups. After endoso$\mathrm{mal} /$ lysosomal escape through the buffer capability of $\mathrm{H}_{\mathrm{n}}$ sequence, NLS sequence in REDV-TAT-NLS- $\mathrm{H}_{12} /$ pZNF580 complexes enhanced the nuclear location ability of pZNF580. Therefore, the peptide-based gene carriers, especially REDV-TAT-NLS- $\mathrm{H}_{12}$, could efficiently transfect HUVECs, improved the escape ability from endosome/lysosome, and enhanced the gene expression level successfully.

\section{Quantitative real-time RT-PCR assay}

The expression of ZNF580 mRNA in transfected HUVECs was measured by Real-Time RT-PCR analysis technique. The results of ZNF580 mRNA expression were shown in Fig. 11. The relative ZNF580 mRNA expression levels of REDV-TAT-NLS- $\mathrm{H}_{0} /$ pZNF580, REDV-TATNLS- $\mathrm{H}_{4} /$ pZNF580, REDV-TAT-NLS- $\mathrm{H}_{8} /$ pZNF580 and REDV-TAT-NLS- $\mathrm{H}_{12} /$ pZNF580 complexes groups were much higher than the control group (Fig. 11(E)). Compared with REDV-TAT-NLS- $\mathrm{H}_{0} /$ pZNF580 complexes group, the HUVECs treated with REDV-TAT-NLS- $\mathrm{H}_{\mathrm{n}}$ / 
(1)

$0 \mathrm{~h}$

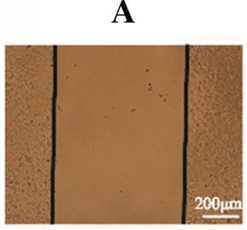

$6 \mathrm{~h}$
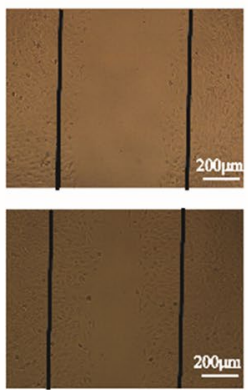

B
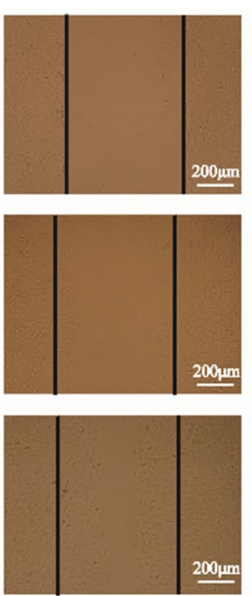

C
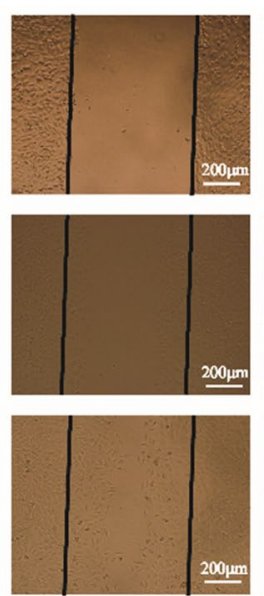

D
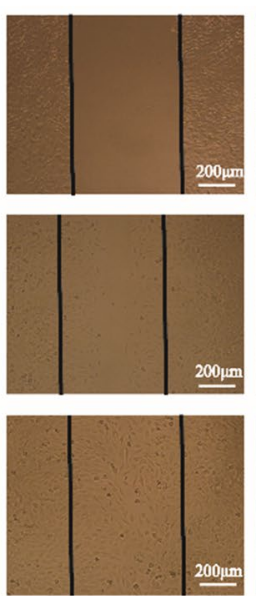

E
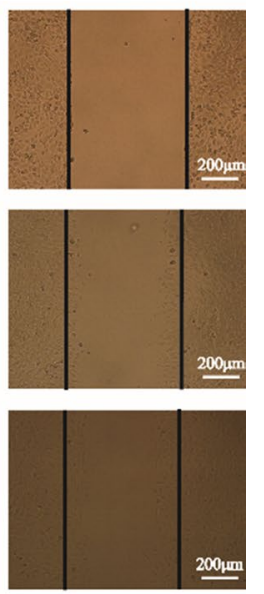

(2)

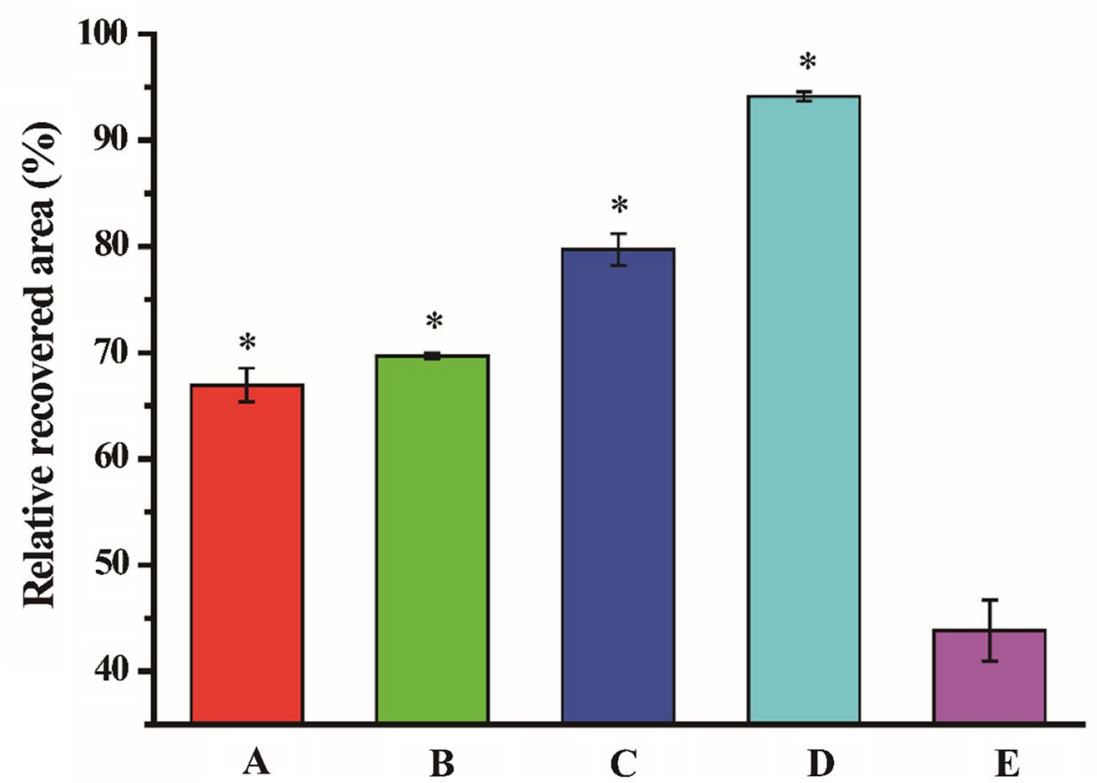

Fig. 7 Recovered process of HUVECs at different time points (1) and the relative recovered area after $12 \mathrm{~h}$ calculated by Image-J software (2). (A) HUVECs treated with REDV-TAT-NLS-H $/$ /pZNF580 complexes, (B) HUVECs treated with REDV-TAT-NLS-H 4 /pZNF580 complexes, (C) HUVECs treated with REDV-TAT-NLS-H 8 /pZNF580 complexes, (D) HUVECs treated with REDV-TAT-NLS-H 12 /pZNF580 complexes, (E) HUVECs treated with pZNF580 as a control group (mean $\pm \mathrm{SD}, \mathrm{n}=3,{ }^{*} \mathrm{P}<0.05$ vs. control group)

pZNF580 complexes showed high ZNF580 mRNA expression level. REDV-TAT-NLS- H $_{12} /$ PZNF580 complexes group expressed highest ZNF580 mRNA, which highlights the effect of $H_{n}$ sequence in gene carriers. These results proved that the efficient gene delivery of REDV-TAT-NLS- $\mathrm{H}_{\mathrm{n}} / \mathrm{pZNF580}$ complexes in mRNA level was similar to the results of western blot analysis.

\section{Cellular uptake and CLSM}

To evaluate the cellular uptake capability of these complexes in HUVECs, different gene complexes were cultured with cells for $4 \mathrm{~h}$ and detected by a flow cytometry. As shown in Fig. 12, the cellular uptake of gene complexes with $H_{n}$ sequence was above $95 \%$ and much higher than that of REDV-TAT-NLS- $\mathrm{H}_{0} / \mathrm{Cy} 5$-oligonucleotide complexes. The MFI of REDV-TAT-NLS- $\mathrm{H}_{\mathrm{n}} / \mathrm{Cy} 5$-oligonucleotide complexes groups also showed a similar tendency. The MFI values increased along with $\mathrm{H}_{n}$ sequence length increased from 4 to 12 . Especially, the REDVTAT-NLS- $\mathrm{H}_{12} /$ Cy5-oligonucleotide complexes group demonstrated significantly high MFI value $(M F I=1215)$, which was nearly 14 folds to REDV-TAT-NLS- $\mathrm{H}_{0}$ / 
(1)
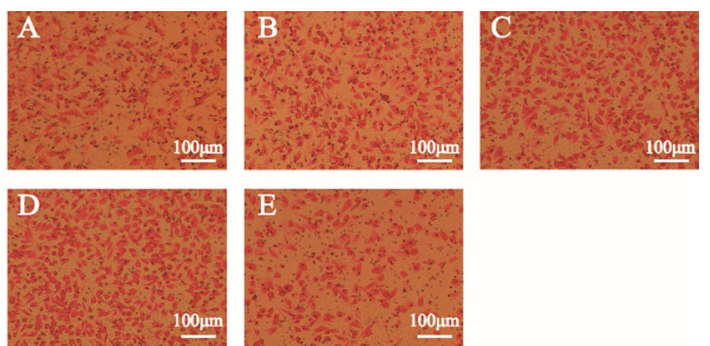

(2)

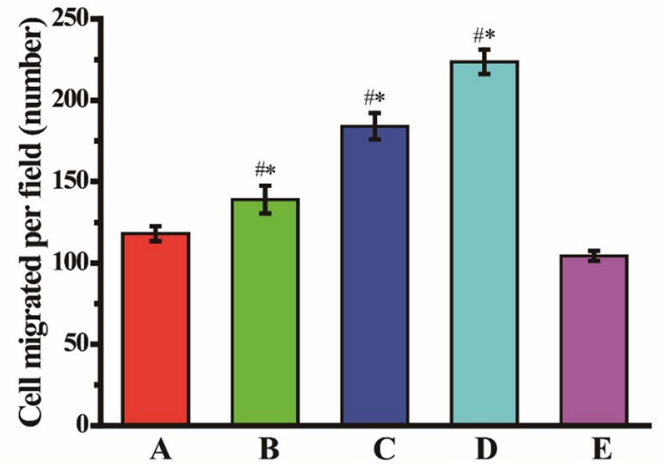

Fig. 8 Migration assay of HUVECs through a transwell chamber over $6 \mathrm{~h} \mathrm{(1)}$ and the average number of cells migrating (2). (A) HUVECs treated with REDV-TAT-NLS-Ho/pZNF580 complexes, (B) HUVECs treated with REDV-TAT-NLS-H $/$ /pZNF580 complexes, (C) HUVECS treated with REDV-TAT-NLS-H/ $/$ pZNF580 complexes, (D) HUVECS treated with REDV-TAT-NLS- H $_{12} /$ pZNF58 80 complexes, (E) ECs treated with pZNF580 as a control group (mean $\pm S D, n=3$, ${ }^{*} P<0.05$ vs. control group). ${ }^{\#} P<0.05$ vs. group $A$

Cy5-oligonucleotide complexes group. This phenomenon could be interpreted that the $\mathrm{H}_{\mathrm{n}}$ sequence was hydrophobic under neutral $\mathrm{pH}$ condition, which facilitated hydrophobic interaction of gene carrier with cell membrane so as to promote cellular uptake [58].

Besides, the MFI of transfected HUASMCs was also evaluated to verify the target function of the gene complexes. In Fig. 12(3), the results showed that the MFI of transfected HUVECs was significantly higher than in HUASMCs, which demonstrated the targeting ability of REDV-TAT-NLS- $\mathrm{H}_{12} / \mathrm{Cy} 5$-oligonucleotide complexes to HUVECs.

Furthermore, the intercellular distribution of Cy5-oligonucleotide in transfected HUVECs was evaluated by CLSM. The intracellular yellow pixels represented the entrapment of REDV-TAT-NLS- $\mathrm{H}_{\mathrm{n}} / \mathrm{Cy} 5$-oligonucleotide complexes in the endosome/lysosome, whereas the intracellular pink pixels illustrated their presence in nucleus. As shown in Fig. 12(4), the nucleus CLR of REDV-TAT$\mathrm{NLS}-\mathrm{H}_{\mathrm{n}} / \mathrm{Cy} 5$-oligonucleotide complexes increased with increasing $\mathrm{H}_{\mathrm{n}}$ sequence length, while the lysosome CLR decreased. These results demonstrated that more complexes with longer $H_{n}$ sequence entered into HUVECs, escaped from endosome/lysosomes into cytoplasm and entered into nucleus. As aforementioned, the $\mathrm{H}_{\mathrm{n}}$ sequence was hydrophobic at $\mathrm{pH}$ 7.4, which was advantageous for cellular uptake. Besides, this $\mathrm{H}_{\mathrm{n}}$ sequence could change to hydrophilic and positive-charged under acid condition in endosome/lysosome. Thus, it could help endosomal/lysosomal membrane rupture and escape owing to the $\mathrm{pH}$ buffer capacity of imidazole ring in $\mathrm{H}_{\mathrm{n}}$ residues $[59,60]$. In addition, the nucleus CLR of REDVTAT-NLS- $\mathrm{H}_{12} /$ Cy5-oligonucleotide complexes was $58.5 \pm 4.0 \%$, which was about sixfold as high as REDVTAT-NLS- $\mathrm{H}_{0} / \mathrm{Cy} 5$-oligonucleotide complexes group. These results indicated that these peptides containing $H_{n}$, REDV and NLS sequences, especially the REDVTAT-NLS- $\mathrm{H}_{12}$ peptide can promote the cellular uptake efficiency, endosome/lysosome escape ability and nuclear location capacity, which could improve the efficiency of gene delivery.

\section{Cellular uptake mechanism}

Gene carriers can enter into cells via several pathways, such as micropinocytosis, clathrin-mediated endocytosis, caveolae-mediated endocytosis and other endocytic pathways [61-64]. To study the cellular uptake mechanism of these REDV-TAT-NLS- $\mathrm{H}_{\mathrm{n}} / \mathrm{pZNF580}$ complexes, different inhibitors were used for particular endocytic pathways. In this paper, three typical endocytosis pathways including clathrin-mediated endocytosis, caveolae-mediated endocytosis and micropinocytosis were studied. Amiloride (Amil) is reported to inhibit the micropinocytosis by blocking the $\mathrm{Na}^{+} / \mathrm{H}^{+}$channels, chlorpromazine (CPZ) can inhibit clathrin-mediated endocytosis by the interruption of clathrin, while filipin (Filip) can inhibit the caveolae-mediated endocytosis via combination with cholesterol [65].

Herein, because of the best results of cellular uptake and intercellular distribution, REDV-TAT-NLS- $\mathrm{H}_{12} /$ Cy5-oligonucleotide complexes were used to transfect HUVECs to investigate the cellular uptake mechanism. As shown in Fig. 13, a great reduction (about 56\%) occurred when HUVECs were cultured with CPZ for $1 \mathrm{~h}$ before transfection. The cellular uptake reduced approximately 17 and $12 \%$ when HUVECs were pretreated with Amil and Filip, respectively. These results demonstrated that clathrin-mediated endocytosis is the main pathway for cellular uptake of REDV-TAT-NLS- $\mathrm{H}_{12} / \mathrm{Cy} 5$-oligonucleotide complexes. In addition, the caveolae-mediated endocytosis and micropinocytosis were also responsible for the cellular uptake of REDV-TAT-NLS- $\mathrm{H}_{12} / \mathrm{Cy} 5$ oligonucleotide complexes, but they were not the main pathways. The addition of two or three inhibitors in one test group was performed to evaluate the effect of the other pathways. When cells were pre-incubated with these three inhibitors before transfection, the cellular 
(1)
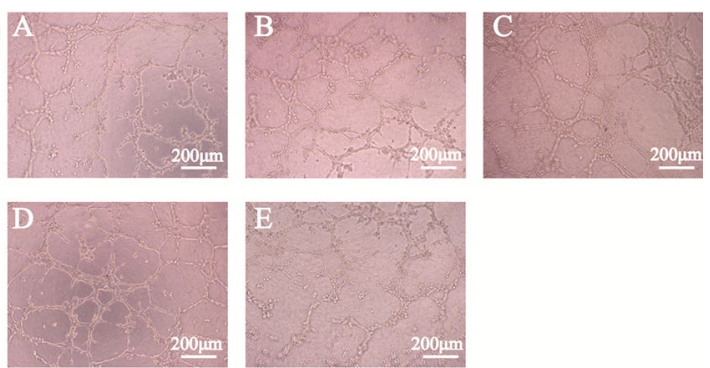

(2)

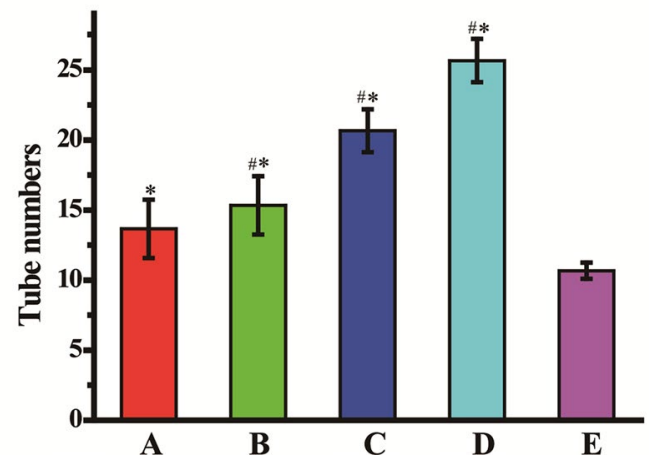

Fig. 9 Images of different REDV-TAT-NLS- $\mathrm{H}_{n} /$ pZNF580 complexes induced in vitro tube formation of HUVECs (1) and tube number formed in different group (2). (A) REDV-TAT-NLS-Ho/pZNF580 complexes treated group, (B) REDV-TAT-NLS-H ${ }_{4} /$ pZNF580 complexes treated group, (C) REDV-TAT-NLS-H $/$ /pZNF580 complexes treated group, (D) REDV-TAT-NLS-H 12 /pZNF580 complexes treated group, (E) pZNF580 treated group as a control group (mean $\pm S D, n=3$, ${ }^{*} \mathrm{P}<0.05$ vs. control group). ${ }^{\#} P<0.05$ vs. group $A$
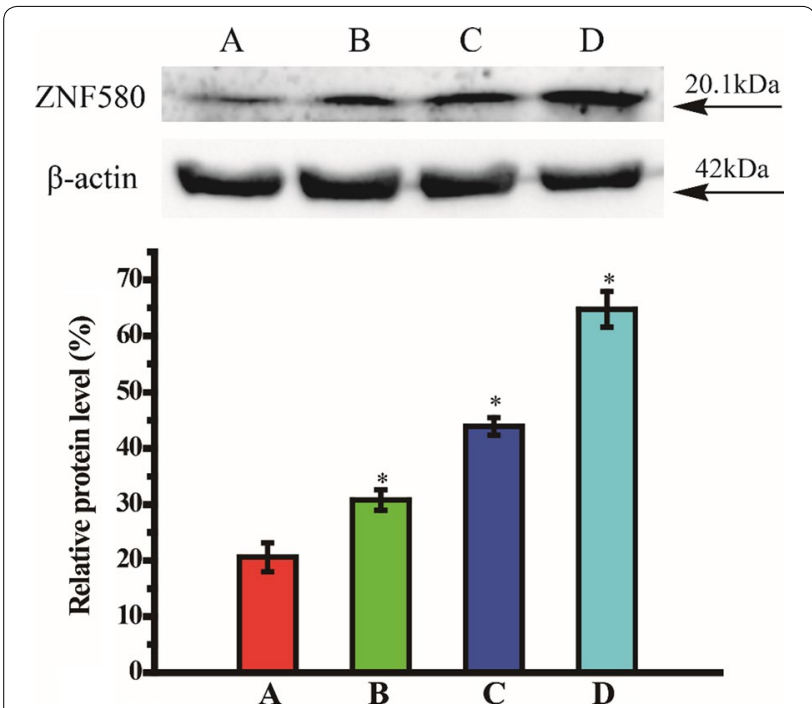

Fig. 10 The western blot analysis of ZNF580 protein expression in HUVECs treated with different REDV-TAT-NLS- $H_{n} /$ pZNF580 complexes. (A) REDV-TAT-NLS-H $/$ /pZNF580 complexes treated group, (B) REDVTAT-NLS- $\mathrm{H}_{4} /$ pZNF580 complexes treated group, (C) REDV-TAT-NLS-H ${ }_{8} /$ pZNF580 complexes treated group, (D) REDV-TAT-NLS-H $12 /$ pZNF580 complexes treated group (mean $\pm S D, n=3$, ${ }^{P}<<0.05$ vs. control group A)

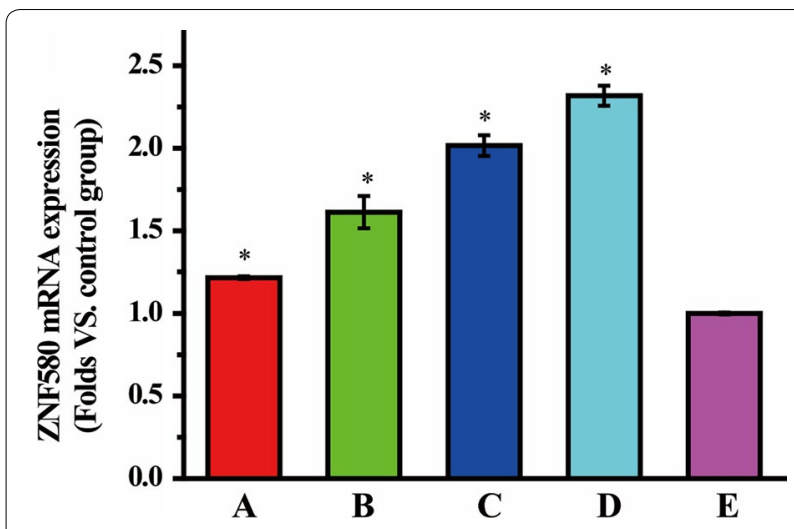

Fig. 11 Quantitative mRNA expression of HUVECs transfected by different REDV-TAT-NLS-H ${ }_{n} /$ pZNF580 complexes. (A) REDV-TAT-NLS$\mathrm{H}_{0} /$ pZNF580 complexes treated group, (B) REDV-TAT-NLS-H 4 /pZNF580 complexes treated group, (C) REDV-TAT-NLS-H H $_{8}$ pZNF580 complexes treated group, (D) REDV-TAT-NLS-H $12 /$ pZNF580 complexes treated group, (E) pZNF580 treated group as a control group (mean \pm SD, $n=3,{ }^{*} P<0.05$ vs. control group)

uptake of REDV-TAT-NLS- $\mathrm{H}_{12} / \mathrm{Cy} 5$-oligonucleotide complexes still remained $36.8 \%$. In addition, the cellular uptake of only REDV treated group decreased almost $10 \%$, which means that the targeting REDV peptide contributed to the cellular uptake (10\%) of REDV-TAT-NLS$\mathrm{H}_{12}$ /Cy5-oligonucleotide complexes. The above results indicated that some other endocytic pathways existed because the cellular uptake still remained about 27\% except for three inhibitors and REDV mediated endocytosis. In conclusion, the cellular uptake mechanism was multiple action of different endocytosis pathways, and the clathrin-mediated endocytosis was the major internalization pathway of REDV-TAT-NLS- $\mathrm{H}_{12} / \mathrm{Cy} 5$-oligonucleotide complexes in HUVECs.

\section{In vivo angiogenesis assay}

To further investigate the angiogenesis ability in vivo, the transfected HUVECs were mixed with Matrigel and subcutaneously implanted into mice. After 4 days, Matrigel implants were removed and sectioned. H\&E staining and anti-CD31 staining were performed to reveal the formation of microvessel structure, and the results were shown in Fig. 14. HUVECs, which were transfected with REDV-TAT-NLS- $\mathrm{H}_{\mathrm{n}} /$ pZNF580 complexes, showed obvious microvessel structures. A great number of luminal structures were observed in the implants containing REDV-TAT-NLS- $\mathrm{H}_{12} /$ pZNF580 complexes transfected cells compared with REDV-TAT-NLS- $\mathrm{H}_{0} / \mathrm{pZNF580} \mathrm{com-}$ plexes group (Fig. 14(A), (D)). In contrast, the cells only treated with pZNF580 showed few microvessel structures (Fig. 14(E)), which means its poor tube formation ability. To further characterize the microvessel structure 


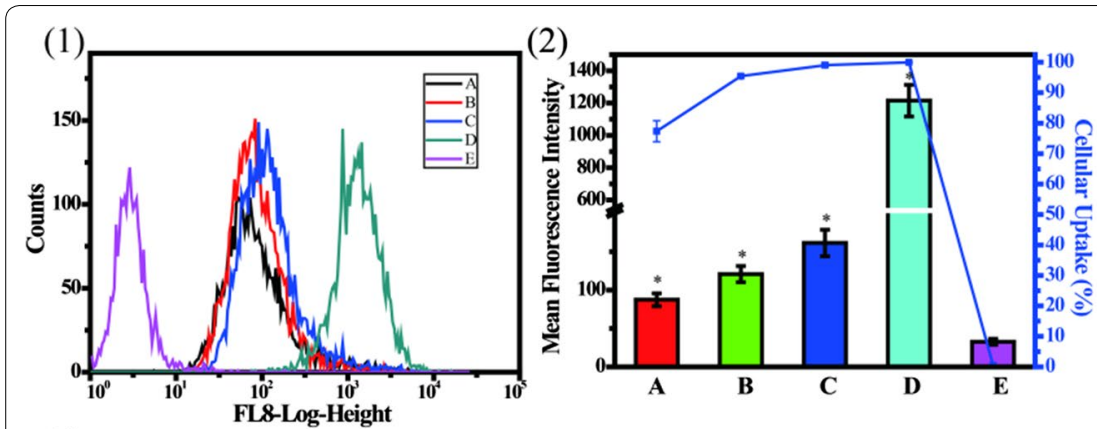

(4)

A

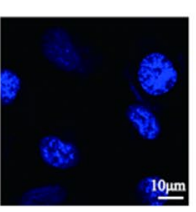

B

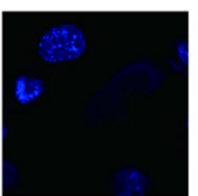

$\mathrm{C}$

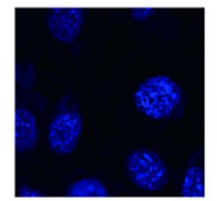

$\mathrm{D}$

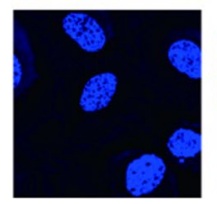

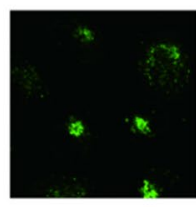
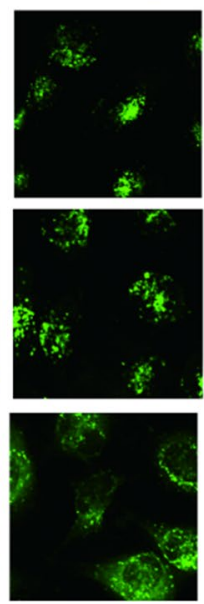

(2)

Cy5-oligonucleotide Bright Field
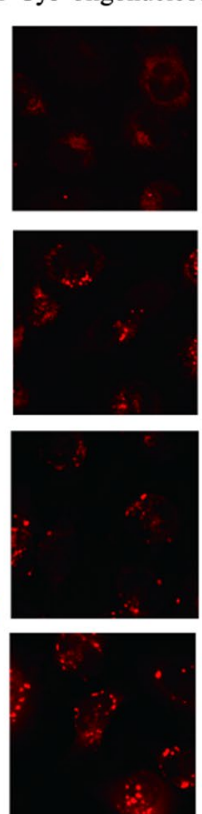
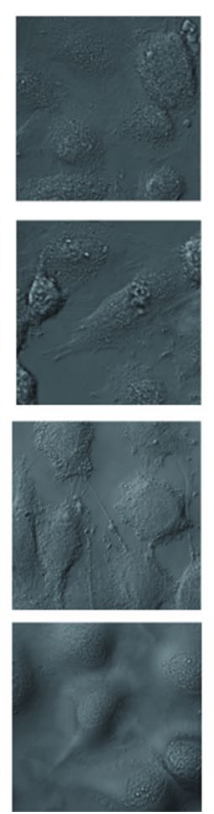

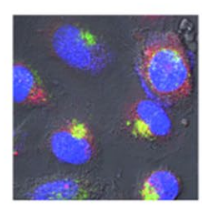

(3)

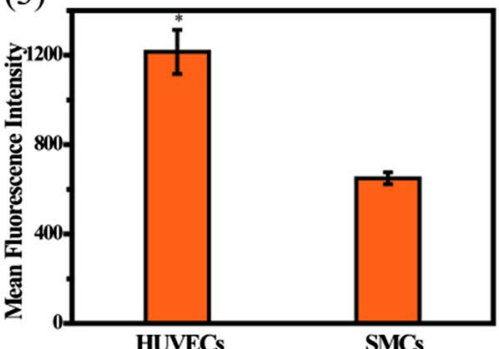

Co-localization ratio of Cy5-oligonucleotide and LysoTracker Green

Co-localization ratio of Cy5-oligonucleotide and Hoechst 33342

$17.6 \pm 3.6 \%$

$9.2 \pm 2.9 \%$

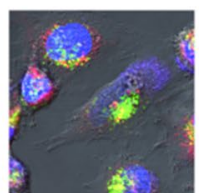

$21.6 \pm 1.1 \%$

$14.7 \pm 3.0 \%$

$15.9 \pm 0.9 \%$

$29.8 \pm 2.1 \%$

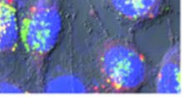

$4.6 \pm 0.6 \%$

$58.5 \pm 4.0 \%$

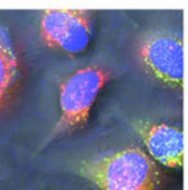

Fig. 12 Cellular uptake analysis of various REDV-TAT-NLS-H $\mathrm{n}_{\mathrm{n}} / \mathrm{Cy}$ 5-oligonucleotide complexes after $4 \mathrm{~h}$ transfection (1), percentages of cellular uptake and mean fluorescence intensity (MFI) measured by flow cytometry (2), mean fluorescence intensity of HUVECs and HUASMCs transfected by REDV-TAT-NLS-H 12 /Cy5-oligonucleotide complexes (3), and CLSM images of intracellular trafficking of various REDV-TAT-NLS-H $\mathrm{n}_{\mathrm{n}} / \mathrm{Cy}_{5}$-oligonucleotide complexes (4). (A) REDV-TAT-NLS-H $/$ /Cy5-oligonucleotide complexes treated group, (B) REDV-TAT-NLS-H//Cy5-oligonucleotide complexes treated group, (C) REDV-TAT-NLS-H $/ 8$ Cy5-oligonucleotide complexes treated group, (D) REDV-TAT-NLS-H $12 / C y 5$-oligonucleotide complexes treated group, (E) Cy5-oligonucleotide treated group as a control group (mean $\pm \mathrm{SD}, \mathrm{n}=3$, ${ }^{*} \mathrm{P}<0.05$ vs. control group)

clearly, Fig. 14(2) showed the images of immunofluorescence staining with anti-CD31 for HUVECs. These results indicated that the expression pZNF580 could promote angiogenesis in vivo. In consistent with the results of the in vitro tube formation assay, the REDV-TAT-NLS$\mathrm{H}_{12}$ /pZNF580 complexes could obviously enhance the angiogenesis ability both in vitro and in vivo.

\section{Discussion}

In recent years, gene therapy offers a promising alternative for the treatment of cardiovascular diseases. The development of non-virus gene carriers with low cytotoxicity and high safety is especially necessary for vascularization. Cationic peptides are synthesized from natural amino acids, which are widely used as gene carriers. Compared with other gene carriers, the peptidebased gene carriers exhibit relatively low cytotoxicity and good biocompatibility. As a kind of widely used CPPs, the arginine-rich TAT peptide shows high ability of crossing cell membrane to overcome the first barrier of gene delivery. Herein, three peptides with integrated sequence of REDV-YGRKKRRQRRR-PKKKRKV- $\mathrm{H}_{\mathrm{n}}$ (REDV-TAT$\mathrm{NLS}-\mathrm{H}_{\mathrm{n}}, \mathrm{n}=4,8$ and 12) were designed as the gene carrier for pZNF580 plasmid, and REDV-YGRKKRRQRRR-PKKKRKV- $\mathrm{H}_{0}$ without oligohistidine sequence was used as a control. In order to deliver genes into HUVECs selectively, REDV peptide was inserted into the peptide sequence due to its specific recognition of $\alpha 4 \beta 1$ 


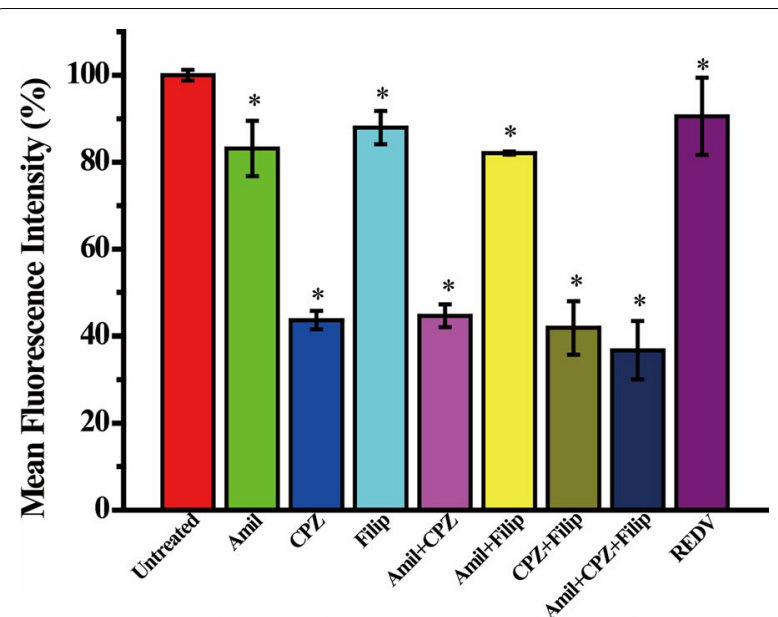

Fig. 13 Effects of endocytic inhibitors on cellular uptake of REDVTAT-NLS- $\mathrm{H}_{12} / \mathrm{Cy} 5$-oligonucleotide complexes on HUVECS. HUVECS treated with REDV-TAT-NLS-H ${ }_{12} /$ Cy5-oligonucleotide complexes without inhibitors as a control group (mean $\pm S D, n=3, * P<0.05$ vs. control group)

integrin on the membrane of ECs. To increase the endosomal escape ability of the peptide gene carrier, oligohistidine $\mathrm{H}_{\mathrm{n}}$ sequences were used to acquire cationic ions under acid condition especially in endosome/lysosome.

The REDV-TAT-NLS- $\mathrm{H}_{\mathrm{n}} / \mathrm{pZNF580}$ complexes were prepared by adding pZNF580 plasmid to REDV-TATNLS $-\mathrm{H}_{\mathrm{n}}$ solution. The size of REDV-TAT-NLS-H $\mathrm{n} /$ pZNF580 complexes ranged from 117 to $288 \mathrm{~nm}$ and their zeta potential could be regulated by changing the weight ratio of peptide and pZNF580. According to the results of agarose gel electrophoresis, REDV-TATNLS-H ${ }_{0}$, REDV-TAT-NLS-H${ }_{4}$, REDV-TAT-NLS-H $\mathrm{H}_{8}$ and REDV-TAT-NLS-H $\mathrm{H}_{12}$ peptides could completely condense the negative-charged pZNF580 plasmid to form gene complexes at the $\mathrm{w} / \mathrm{w}$ ratio of $2,2,2$ and 3 , respectively. In addition, these peptides exhibited good blood compatibility and less destructed RBCs. The $\mathrm{H}$ residue possesses $\mathrm{pH}$ buffer capacity and hydrophobicity at $\mathrm{pH}$ 7.4. Thus, the positive charge of these peptides decreased when $\mathrm{H}_{\mathrm{n}}$ sequence increased from 4 to 12 . According to the cytotoxicity assay, the relative cell viability of the peptides and their gene complexes was higher than $80 \%$ even at a high concentration $\left(120 \mu \mathrm{g} \mathrm{mL}^{-1}\right)$, which showed a brilliant low cytotoxicity compared with PEI (25 kDa) [66]. The cellular uptake and MFI of the complexes increased when the $H_{n}$ sequence length increased from 4 to 12 . The reason is that the hydrophobicity of gene carriers expedites the hydrophobic interaction with cell membrane, which can promote their cellular internalization [58]. Moreover, the MFI of REDV-TAT-NLS- $\mathrm{H}_{12}$ /
Cy5-oligonucleotide complexes in HUVECs was about twofold as much as that in HUASMCs, which exhibited the specific recognition ability to HUVECs due to REDV in peptide sequence. Compared with the REDV-TATNLS- $\mathrm{H}_{0} /$ pZNF580 complexes, REDV-TAT-NLS- $\mathrm{H}_{\mathrm{n}} /$ pZNF580 complexes showed higher gene delivery and transfection efficiency due to the synergistic effects of the peptide sequences to enhance cellular uptake, endosome/ lysosome escape and nucleus translocation. The results of western blot analysis and PCR analysis also demonstrated the same tendency of ZNF580 expression at the protein level and mRNA level. For the HUVEC migration assay, the migration rate of REDV-TAT-NLS- $\mathrm{H}_{\mathrm{n}}$ / pZNF580 complexes groups was much higher than that of the REDV-TAT-NLS- $\mathrm{H}_{0} /$ pZNF580 group because of their higher transfection efficiency. REDV-TAT-NLS$\mathrm{H}_{12}$ /pZNF580 group showed the highest migration rate (224 migrated cells), which was higher than the standard transfection reagent PEI $25 \mathrm{kDa}$ pZNF580 group [66]. Furthermore, according to the intercellular distribution assay, the REDV-TAT-NLS- $\mathrm{H}_{12} / \mathrm{Cy} 5$-oligonucleotide complexes showed the highest ability of endosome/lysosome escape.

In order to investigate the cellular uptake mechanism of the REDV-TAT-NLS- $\mathrm{H}_{12} / \mathrm{pZNF580}$ complexes, cells were pre-treated with different inhibitors before transfection. The result demonstrated that clathrin-mediated endocytosis was the main pathway for the cellular uptake of REDV-TAT-NLS- $\mathrm{H}_{12}$ /Cy5-oligonucleotide complexes, and other pathways including caveolae-mediated endocytosis, micropinocytosis and other endocytosis pathways also contributed to the cellular uptake. In addition, targeting REDV peptide in REDV-TAT-NLS-H ${ }_{12} / \mathrm{Cy} 5$ oligonucleotide complexes also benefited for the cellular uptake.

To evaluate the tube formation ability of HUVECs treated by REDV-TAT-NLS- $\mathrm{H}_{\mathrm{n}} / \mathrm{pZNF580}$ complexes, the angiogenesis assay was performed both in vitro and in vivo. The cells transfected with the REDV-TAT-NLS$\mathrm{H}_{\mathrm{n}} / \mathrm{pZNF580}$ complexes could enhance the tube formation ability compared with the naked pZNF580 group. The angiogenesis ability of HUVECs transfected by REDV-TAT-NLS- $\mathrm{H}_{12}$ /pZNF580 complexes was the highest among all of the groups. These complexes could efficiently deliver gene into cells.

According to the above results, the multifunctional REDV-TAT-NLS- $\mathrm{H}_{\mathrm{n}}$ micelles could efficiently condense pZNF580, enhance gene delivery ability, and promote the migration, proliferation as well as neovascularization ability of HUVECs, which have great potential in the application of therapeutic vascularization for various vascular diseases. 
(1)
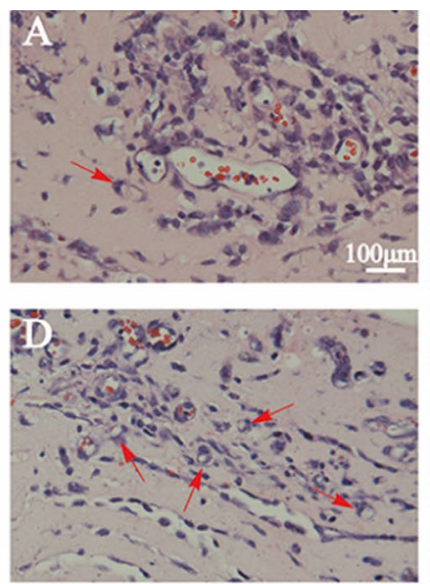

(2)
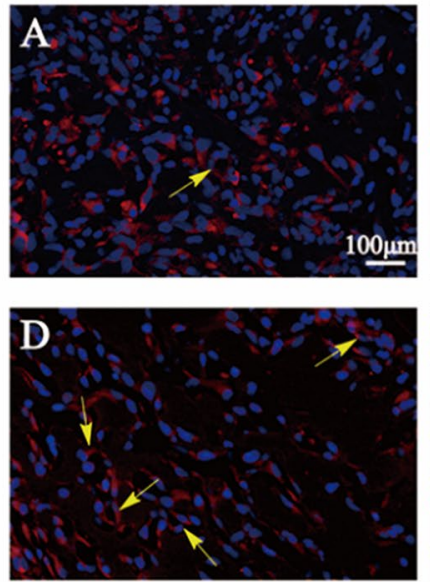
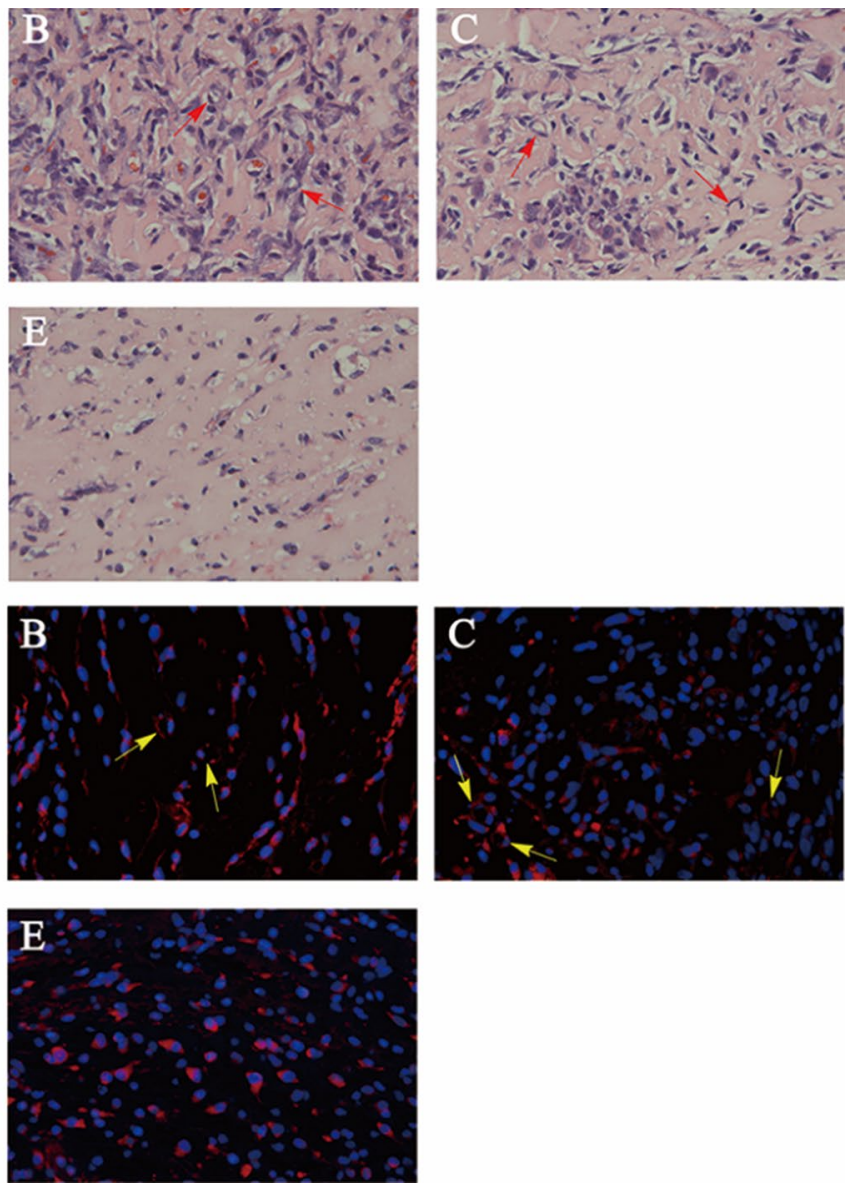

Fig. 14 Neovascularization assay evaluating in vivo tube formation of HUVECs treated with REDV-TAT-NLS-Hn $/$ pZNNF580 complexes. (A) REDV-TATNLS-H ${ }_{0} /$ pZNF580 complexes treated group, (B) REDV-TAT-NLS-H 4 /pZNF580 complexes treated group, (C) REDV-TAT-NLS-H 8 /pZNF580 complexes treated group, (D) REDV-TAT-NLS-H 12 pZNF580 complexes treated group, (E) pZNF580 treated group. Implants were sectioned and stained with hematoxylin and eosin (H\&E) (1) and immunohistochemically stained with anti-CD31 antibody (2)

\section{Conclusion}

In summary, this paper designed the multifunctional targeting peptide sequences of REDV-YGRKKRRQRRRPKKKRKV- $\mathrm{H}_{\mathrm{n}}(\mathrm{n}=4,8$ and 12) as a gene carrier for improving the cellular uptake and gene delivery. TAT peptide and targeting REDV peptide benefited for the cellular uptake of pZNF580 plasmid in HUVECs. And the $H_{n}$ sequence simultaneously improved the internalization efficiency and endosomal escape of REDV-TATNLS- $\mathrm{H}_{\mathrm{n}} /$ pZNF580 complexes, which further enhanced the expression of ZNF580 as well as the proliferation and migration ability of HUVECs. The expression of ZNF580 could enhance the tube formation ability of transfected HUVECs in vivo. Overall, these multifunctional peptide gene carriers provide an outstanding platform for rapid endothelialization and revascularization.

\section{Additional file}

Additional file 1: Figure S1. Hydrodynamic diameter distribution of REDV-TAT-NLS-Hn micelles characterized by DLS. Figure S2. Hydrodynamic diameter distribution of REDV-TAT-NLS-H $\mathrm{H}_{\mathrm{n}} / \mathrm{pZNF580} \mathrm{complexes}$ $(\mathrm{w} / \mathrm{W}=1)$ characterized by DLS. Figure S3. Hydrodynamic diameter distribution of REDV-TAT-NLS- $H_{n} /$ pZNF580 complexes $(w / w=2)$ characterized by DLS. Figure S4. Hydrodynamic diameter distribution of REDVTAT-NLS- $\mathrm{H}_{\mathrm{n}} / \mathrm{pZNF580}$ complexes $(\mathrm{w} / \mathrm{w}=3)$ characterized by DLS. Figure S5. Hydrodynamic diameter distribution of REDV-TAT-NLS- $\mathrm{H}_{n} /$ PZNF580 complexes $(w / W=4)$ characterized by DLS. Figure S6. Hydrodynamic diameter distribution of REDV-TAT-NLS- $H_{n} /$ pZNFF58 complexes $(w / W=5)$ characterized by DLS. 


\section{Authors' contributions}

QL designed the experiments, performed the cell experiments including MTT, transfection assay, cell migration assay, tube formation assay, cellular uptake and CLSM, performed molecular biology experiments including western blot and quantitative real-time PCR, did animal experiments, and drafted manuscript. XFH prepared peptides and characterized peptides. YKF conceived research, participated in experimental design, and participated in manuscript writing. JTG, XKR, CCS and WCZ helped to improve the manuscript. All authors read and approved the final manuscript.

\section{Author details \\ 1 School of Chemical Engineering and Technology, Tianjin University, Tianjin 300350, China. ${ }^{2}$ Collaborative Innovation Center of Chemical Science and Chemical Engineering (Tianjin), Tianjin 300350, China. ${ }^{3}$ School of Oph- thalmology, \& Optometry, Eye Hospital, School of Biomedical Engineering, Wenzhou Medical University, Wenzhou 325011, Zhejiang, China. ${ }^{4}$ Wenzhou Institute of Biomaterials and Engineering, CNITECH, CAS, Wenzhou 325011, Zhejiang, China. ${ }^{5}$ Department of Physiology and Pathophysiology, Logistics University of Chinese People's Armed Police Force, Tianjin 300309, China. ${ }^{6}$ Key Laboratory of Systems Bioengineering (Ministry of Education), Tianjin Univer- sity, Tianjin 300072, China.}

\section{Acknowledgements}

This project was supported by National Key R\&D Program of China (Grant No. 2016YFC1100300), National Natural Science Foundation of China (Grant Nos. 31370969 and 51673145), International Science \& Technology Cooperation Program of China (Grant No. 2013DFG52040).

\section{Competing interests}

The authors declare that they have no competing interests.

\section{Availability of data and materials}

All data generated or analyzed during this study are included in the article.

\section{Consent for publication}

All the co-authors were aware of this submission and approve for publication.

\section{Ethical approval and consent to participate}

This study was performed with the "Guide for the protection and use of experimental animals" and was approved by the Committee of Ethics of Armed Police Logistics College.

\section{Publisher's Note}

Springer Nature remains neutral with regard to jurisdictional claims in published maps and institutional affiliations.

Received: 17 September 2017 Accepted: 19 March 2018

Published online: 26 March 2018

\section{References}

1. Brewster LP, Brey EM, Greisler HP. Cardiovascular gene delivery: the good road is awaiting. Adv Drug Deliv Rev. 2006;58:604-29.

2. Ren X, Feng Y, Guo J, Wang H, Li Q, Yang J, Hao X, Lv J, Ma N, Li W. Surface modification and endothelialization of biomaterials as potential scaffolds for vascular tissue engineering applications. Chem Soc Rev. 2015;44:5680-742.

3. Khan M, Yang J, Shi CC, Feng YK, Zhang WC, Gibney K, Tew GN. Manipulation of polycarbonate urethane bulk properties via incorporated zwitterionic polynorbornene for tissue engineering applications. RSC Adv. 2015;5:11284-92.

4. Wang HY, Feng YK, Fang ZC, Xiao RF, Yuan WJ, Khan M. Fabrication and characterization of electrospun gelatin-heparin nanofibers as vascular tissue engineering. Macromol Res. 2013;21:860-9.

5. Shi C, Yuan W, Khan M, Li Q, Feng Y, Yao F, Zhang W. Hydrophilic PCU scaffolds prepared by grafting PEGMA and immobilizing gelatin to enhance cell adhesion and proliferation. Mater Sci Eng C. 2015;50:201-9.
6. Gao B, Feng Y, Lu J, Zhang L, Zhao M, Shi C, Khan M, Guo J. Grafting of phosphorylcholine functional groups on polycarbonate urethane surface for resisting platelet adhesion. Mater Sci Eng C. 2013;33:2871-8.

7. Zhou W, Feng Y, Yang J, Fan J, LV J, Zhang L, Guo J, Ren X, Zhang W. Electrospun scaffolds of silk fibroin and poly(lactide-co-glycolide) for endothelial cell growth. J Mater Sci Mater Med. 2015; 26:56. https://doi. org/10.1007/s10856-015-5386-6.

8. Chen WC, Ko CL. Roughened titanium surfaces with silane and further RGD peptide modification in vitro. Mater Sci Eng C. 2013;33:2713-22.

9. Khan M, Yang J, Shi C, LV J, Feng Y, Zhang W. Surface tailoring for selective endothelialization and platelet inhibition via a combination of SI-ATRP and click chemistry using Cys-Ala-Gly-peptide. Acta Biomater. 2015;20:69-81.

10. Yu S, Gao Y, Mei X, Ren T, Liang S, Mao Z, Gao C. Preparation of an arg-gluasp-val peptide density gradient on hyaluronic acid-coated poly(epsiloncaprolactone) film and its influence on the selective adhesion and directional mgration of endothelial cells. ACS Appl Mater Interfaces. 2016:8:29280-8.

11. Wang W, Guo L, Yu Y, Chen Z, Zhou R, Yuan Z. Peptide REDV-modified polysaccharide hydrogel with endothelial cell selectivity for the promotion of angiogenesis. J Biomed Mater Res Part A. 2015;103:1703-12.

12. Wei Y, Zhang JX, Ji Y, Ji J. REDV/rapamycin-loaded polymer combinations as a coordinated strategy to enhance endothelial cells selectivity for a stent system. Colloids Surf B. 2015;136:1166-73.

13. Hao X, Li Q, Lv J, Yu L, Ren X, Zhang L, Feng Y, Zhang W. CREDVW-linked polymeric micelles as a targeting gene transfer vector for selective transfection and proliferation of endothelial cells. ACS Appl Mater Interfaces. 2015;7:12128-40

14. Li Q, Hao XF, LV J, Ren XK, Zhang KY, Ullah I, Feng YK, Shi CC, Zhang WC. Mixed micelles obtained by co-assembling comb-like and grafting copolymers as gene carriers for efficient gene delivery and expression in endothelial cells. J Mater Chem B. 2017;5:1673-87.

15. Yang J, Hao X, Li Q, Akpanyung M, Nejjari A, Neve AL, Ren X, Guo J, Feng Y, Shi C, Zhang W. CAGW peptide- and PEG-modified gene carrier for selective gene delivery and promotion of angiogenesis in HUVECs in vivo. ACS Appl Mater Interfaces. 2017;9:4485-97.

16. Lv J, Hao X, Li Q, Akpanyung M, Nejjari A, Neve AL, Ren X, Feng Y, Shi C, Zhang W. Star-shaped copolymer grafted PEI and REDV as a gene carrier to improve migration of endothelial cells. Biomater Sci. 2017;5:511-22.

17. Li SD, Huang L. Non-viral is superior to viral gene delivery. J Control Release. 2007;123:181-3.

18. He H, Bai Y, Wang J, Deng Q, Zhu L, Meng F, Zhong Z, Yin L. Reversibly cross-linked polyplexes enable cancer-targeted gene delivery via self-promoted DNA release and self-diminished toxicity. Biomacromol. 2015;16:1390-400.

19. Zhu Y, Zheng $X, Y u$ B, Yang W, Zhao N, Xu F. Efficient gene carriers composed of 2-hydroxypropyl-beta-cyclodextrin, ethanolamine-functionalized poly(glycidyl methacrylate), and poly((2-dimethyl amino)ethyl methacrylate) by combination of ATRP and click chemistry. Macromol Biosci. 2014;14:1135-48.

20. Qiu N, Liu X, Zhong Y, Zhou Z, Piao Y, Miao L, Zhang Q, Tang J, Huang L, Shen $Y$. Esterase-activated charge-reversal polymer for fibroblast-exempt cancer gene therapy. Adv Mater. 2016;28:10613-22.

21. Wong SY, Pelet JM, Putnam D. Polymer systems for gene delivery-past, present, and future. Prog Polym Sci. 2007;32:799-837.

22. Stewart MP, Lorenz A, Dahlman J, Sahay G. Challenges in carrier-mediated intracellular delivery: moving beyond endosomal barriers. Wiley Interdiscip Rev Nanomed Nanobiotechnol. 2016;8:465-78.

23. Jones $\mathrm{CH}$, Chen CK, Ravikrishnan A, Rane S, Pfeifer BA. Overcoming nonviral gene delivery barriers: perspective and future. Mol Pharm. 2013;10:4082-98.

24. Okholm AH, Kjems J. DNA nanovehicles and the biological barriers. Adv Drug Deliv Rev. 2016;106:183-91.

25. Trabulo S, Cardoso AL, Mano M, De Lima MC. Cell-penetrating peptidesmechanisms of cellular uptake and generation of delivery systems. Pharmaceuticals. 2010;3:961-93.

26. Stewart KM, Horton KL, Kelley SO. Cell-penetrating peptides as delivery vehicles for biology and medicine. Org Biomol Chem. 2008:6:2242-55. 
27. Kato T, Yamashita H, Misawa T, Nishida K, Kurihara M, Tanaka M, Demizu Y, Oba M. Plasmid DNA delivery by arginine-rich cell-penetrating peptides containing unnatural amino acids. Bioorg Med Chem. 2016;24:2681-7.

28. Reissmann S. Cell penetration: scope and limitations by the application of cell-penetrating peptides. J Pept Sci. 2014;20:760-84.

29. Zaro JL, Shen WC. Cationic and amphipathic cell-penetrating peptides (CPPs): their structures and in vivo studies in drug delivery. Front Chem Sci Eng. 2015;9:407-27.

30. Yu X, Gou X, Wu P, Han L, Tian D, Du F, Chen Z, Liu F, Deng G, Chen AT, et al. Activatable protein nanoparticles for targeted delivery of therapeutic peptides. Adv Mater. 2018. https://doi.org/10.1002/adma.201705383.

31. Copolovici D, Langel K, Eriste E, Langel Ü. Cell-penetrating peptides: design, synthesis, and applications. ACS Nano. 2014;8:1972-94.

32. Zhang W, Mao Z, Gao C. Preparation of TAT peptide-modified poly(N-isopropylacrylamide) microgel particles and their cellular uptake, intracellular distribution, and influence on cytoviability in response to temperature change. J Colloid Interface Sci. 2014;434:122-9.

33. Poon IK, Jans DA. Regulation of nuclear transport: central role in development and transformation? Traffic. 2005;6:173-86.

34. Egorova AA, Kiselev AV. Peptide modules for overcoming barriers of nucleic acids transport to cells. Curr Top Med Chem. 2015;16:330-42.

35. Kim BK, Kang H, Doh KO, Lee SH, Park JW, Lee SJ, Lee TJ. Homodimeric SV40 NLS peptide formed by disulfide bond as enhancer for gene delivery. Bioorg Med Chem Lett. 2012;22:5415-8.

36. Zanta MA, Belguise-Valladier P, Behr JP. Gene delivery: a single nuclear localization signal peptide is sufficient to carry DNA to the cell nucleus. Proc Natl Acad Sci USA. 1999;96:91-6.

37. Qu W, Qin SY, Ren S, Jiang XJ, Zhuo RX, Zhang XZ. Peptide-based vector of VEGF plasmid for efficient gene delivery in vitro and vessel formation in vivo. Bioconjug Chem. 2013;24:960-7.

38. Gao M, Fan F, Li D, Yu Y, Mao K, Sun T, Qian H, Tao W, Yang X. Tumor acidity-activatable TAT targeted nanomedicine for enlarged fluorescence/ magnetic resonance imaging-guided photodynamic therapy. Biomaterials. 2017;133:165-75.

39. Wang XL, Ramusovic S, Nguyen T, Lu ZR. Novel polymerizable surfactants with $\mathrm{pH}$-sensitive amphiphilicity and cell membrane disruption for efficient siRNA delivery. Bioconjug Chem. 2007;18:2169-77.

40. Li Z, Li J, Huang J, Zhang J, Cheng D, Shuai X. Synthesis and characterization of ph-responsive copolypeptides vesicles for siRNA and chemotherapeutic drug co-delivery. Macromol Biosci. 2015;15:1497-506.

41. Mishra D, Kang HC, Bae YH. Reconstitutable charged polymeric (PLGA)(2)-b-PEl micelles for gene therapeutics delivery. Biomaterials. 2011;32:3845-54.

42. He Y, Cheng G, Xie L, Nie Y, He B, Gu Z. Polyethyleneimine/DNA polyplexes with reduction-sensitive hyaluronic acid derivatives shielding for targeted gene delivery. Biomaterials. 2013;34:1235-45.

43. Mastorakos P, Kambhampati SP, Mishra MK, Wu T, Song E, Hanes J, Kannan RM. Hydroxyl PAMAM dendrimer-based gene vectors for transgene delivery to human retinal pigment epithelial cells. Nanoscale. 2015;7:3845-56.

44. Guan LM, Huang SP, Chen Z, Li YC, Liu K, Liu Y, Du LB. Low cytotoxicity fluorescent PAMAM dendrimer as gene carriers for monitoring the delivery of siRNA. J Nanopart Res. 2015;17:385. https://doi.org/10.1007/ s11051-015-3185-0.

45. Salmasi Z, Shier WT, Hashemi M, Mahdipour E, Parhiz H, Abnous K, Ramezani M. Heterocyclic amine-modified polyethylenimine as gene carriers for transfection of mammalian cells. Eur J Pharm Biopharm. 2015:96:76-88.

46. Asayama S, Sekine T, Kawakami H, Nagaoka S. Design of aminated poly(1vinylimidazole) for a new $\mathrm{pH}$-sensitive polycation to enhance cell-specific gene delivery. Bioconjug Chem. 2007;18:1662-7.

47. Zhang X, Chen D, Ba S, Chang J, Zhou J, Zhao H, Zhu J, Zhao X, Hu H, Qiao M. Poly(L-histidine) based copolymers: effect of the chemically substituted L-histidine on the physio-chemical properties of the micelles and in vivo biodistribution. Colloids Surf B. 2016;140:176-84.
48. Zhang Q, Gao H, He Q. Taming cell penetrating peptides: never too old to teach old dogs new tricks. Mol Pharm. 2015;12:3105-18.

49. Yim MJ, Kim JE, Ahn CH, Kim HA, Lee M, Chae SY. Conjugation of histidine derivatives to PEGylated poly(L-lysine-CO-L-phenylalanine) copolymer as a non-viral gene carrier. Macromol Res. 2010;18:545-50.

50. Luo Y, Hu W, Xu R, Hou B, Zhang L, Zhang W. ZNF580, a novel C2H2 zincfinger transcription factor, interacts with the TGF-beta signal molecule Smad2. Cell Biol Int. 2011;35:1153-7.

51. Wei S, Huang J, Li Y, Zhao J, Luo Y, Meng X, Sun H, Zhou X, Zhang M, Zhang W. Novel zinc finger transcription factor ZFP580 promotes differentiation of bone marrow-derived endothelial progenitor cells into endothelial cells via eNOS/NO pathway. J Mol Cell Cardiol. 2015;87:17-26.

52. Sun HY, Wei SP, Xu RC, Xu PX, Zhang WC. Sphingosine-1-phosphate induces human endothelial VEGF and MMP-2 production via transcription factor ZNF580: novel insights into angiogenesis. Biochem Biophys Res Commun. 2010;395:361-6.

53. Tai Z, Wang X, Tian J, Gao Y, Zhang L, Yao C, Wu X, Zhang W, Zhu Q, Gao S. Biodegradable stearylated peptide with internal disulfide bonds for efficient delivery of siRNA in vitro and in vivo. Biomacromolecules. 2015:16:1119-30

54. Bilalis P, Tziveleka LA, Varlas $\mathrm{S}$, latrou H. pH-sensitive nanogates based on poly(L-histidine) for controlled drug release from mesoporous silica nanoparticles. Polym Chem. 2016;7:1475-85.

55. Xie RL, Jang YJ, Xing L, Zhang BF, Wang FZ, Cui PF, Cho MH, Jiang HL. A novel potential biocompatible hyperbranched polyspermine for efficient lung cancer gene therapy. Int J Pharm. 2015;478:19-30.

56. Stewart MJ, Plautz GE, Del Buono L, Yang ZY, Xu L, Gao X, Huang L, Nabel EG, Nabel GJ. Gene transfer in vivo with DNA-liposome complexes: safety and acute toxicity in mice. Hum Gene Ther. 1992;3:267-75.

57. Auerbach R, Lewis R, Shinners B, Kubai L, Akhtar N. Angiogenesis assays: a critical overview. Clin Chem. 2003;49:32-40.

58. Zhu L, Simpson JM, Xu X, He H, Zhang D, Yin L. Cationic polypeptoids with optimized molecular characteristics toward efficient nonviral gene delivery. ACS Appl Mater Interfaces. 2017;9:23476-86.

59. Qiu L, Qiao M, Chen Q, Tian C, Long M, Wang M, Li Z, Hu W, Li G, Cheng $L$, et al. Enhanced effect of $\mathrm{pH}$-sensitive mixed copolymer micelles for overcoming multidrug resistance of doxorubicin. Biomaterials. 2014;35:9877-87.

60. Li Z, Qiu L, Chen Q, Hao T, Qiao M, Zhao H, Zhang J, Hu H, Zhao X, Chen D, Mei L. pH-sensitive nanoparticles of poly(L-histidine)-poly(lactide-coglycolide)-tocopheryl polyethylene glycol succinate for anti-tumor drug delivery. Acta Biomater. 2015;11:137-50.

61. Madani F, Lindberg S, Langel U, Futaki S, Graslund A. Mechanisms of cellular uptake of cell-penetrating peptides. J Biophys. 2011. https://doi. org/10.1155/2011/414729.

62. Khalil IA. Uptake pathways and subsequent intracellular trafficking in nonviral gene delivery. Pharmacol Rev. 2006;58:32-45.

63. Koren E, Torchilin VP. Cell-penetrating peptides: breaking through to the other side. Trends Mol Med. 2012;18:385-93.

64. Kastl L, Sasse D, Wulf V, Hartmann R, Mircheski J, Ranke C, CarregalRomero S, Martinez-Lopez JA, Fernandez-Chacon R, Parak WJ, et al. Multiple internalization pathways of polyelectrolyte multilayer capsules into mammalian cells. ACS Nano. 2013;7:6605-18.

65. Guo T, Zhang Y, Zhao J, Zhu C, Feng N. Nanostructured lipid carriers for percutaneous administration of alkaloids isolated from Aconitum sinomontanum. J Nanobiotechnol. 2015;13:47. https://doi.org/10.1186/ s12951-015-0107-3.

66. Yang J, Liu W, LV J, Feng Y, Ren X, Zhang W. REDV-polyethyleneimine complexes for selectively enhancing gene delivery in endothelial cells. J Mater Chem B. 2016:4:3365-76. 